\title{
EFSUMB Guidelines on Interventional Ultrasound (INVUS), Part V EUS-Guided Therapeutic Interventions (Long Version)
}

\section{EFSUMB Leitlinien Interventioneller Ultraschall (INVUS), Teil V Endosonografisch gestützte therapeutische Interventionen (Langversion)}

Authors

Affiliations
P. Fusaroli ${ }^{1}$, C. Jenssen ${ }^{2}$, M. Hocke ${ }^{3}$, E. Burmester ${ }^{4}$, E. Buscarini ${ }^{5}$, R. F. Havre ${ }^{6}$, A. Ignee ${ }^{7}$, A. Saftoiu ${ }^{8}$, P. Vilmann ${ }^{9}$, C. P. Nolsøe ${ }^{10}$, D. Nürnberg ${ }^{11}$, M. D’Onofrio ${ }^{12}$, O. H. Gilja ${ }^{13}$, T. Lorentzen $^{10}$, F. Piscaglia ${ }^{14}$, P. S. Sidhu ${ }^{15}$, C. F. Dietrich ${ }^{7} 16$ Affiliation addresses are listed at the end of the article.
Key words
- guidelines
- endoscopic ultrasound
- EUS guidance
- pseudocyst drainage
- cholangiodrainage
- pancreatic duct drainage
- celiac plexus neurolysis

\section{Bibliography}

Dol http://dx.doi.org/ 10.1055/s-0035-1553738 Published online: December 3 , 2015

Ultraschall in Med 2016; 37 : E77-E99 @ $\odot$ Georg Thieme Verlag KG Stuttgart · New York ISSN 0172-4614

\section{Correspondence}

Prof. Dr. med. Christoph

F. Dietrich

Med. Klinik 2,

Caritaskrankenhaus Bad

Mergentheim

Uhlandstr. 7

D-97980 Bad Mergentheim Germany

Tel.: ++ 49/(0)7931/582201/

2200

Fax: ++49/(0)7931/582290

Christoph.dietrich@ckbm.de

\section{Abstract \\ $\nabla$}

The fifth section of the Guidelines on Interventional Ultrasound (INVUS) of the European Federation of Societies for Ultrasound in Medicine and Biology (EFSUMB) assesses the evidence for all the categories of endoscopic ultrasound-guided treatment reported to date. Celiac plexus neurolysis and block, vascular intervention, drainage of fluid collections, drainage of biliary and pancreatic ducts, and experimental tumor ablation techniques are discussed. For each topic, all current evidence has been extensively analyzed and summarized into major recommendations for reader consultation in clinical practice (long version).

\section{Introduction}

This is the second of two guidelines (part IV and V) within the framework of the Guidelines on Interventional Ultrasound (INVUS) of the European Federation of Societies for Ultrasound in Medicine and Biology (EFSUMB) describing endoscopic ultrasound (EUS)-guided diagnostic and therapeutic interventions. Part V deals with endoscopic ultrasound (EUS)-guided therapeutic interventions and gives recommendations for the safe and efficient performance of these advanced techniques based on the available evidence at the time of guideline preparation. It complements part IV, which addresses general aspects of interventional EUS and EUS-guided sampling [1]. The methods of guideline development are described in the introduction to the EFSUMB Guidelines on Interventional Ultrasound [2]. Levels of Evidence (LoE) and Grades of Recommendations (GoR) have been assigned according to the Oxford Centre for Evidence-based Medicine criteria (March 2009 edition) [http://www.cebm.net/oxford-cen-

\section{Zusammenfassung \\ $\nabla$}

Der fünfte Teil der Leitlinien der European Federation of Societies for Ultrasound in Medicine and Biology (EFSUMB) zur interventionellen Sonografie bewertet die Evidenz zu allen endosonografisch gestützten Therapieverfahren, über die bisher publiziert worden ist: Neurolyse und Blockade des Plexus coeliacus, vaskuläre Interventionen, Drainage von Flüssigkeitsansammlungen und nekrotischen Kollektionen, biliäre und Pankreasgangdrainagen sowie experimentelle Techniken zur Tumorablation. Für alle diese Verfahren wurde die aktuelle Evidenz gründlich analysiert und in Form von Empfehlungen zusammengefasst, die den Lesern zur Anwendung im klinischen Alltag zur Verfügung stehen (Langversion).

tre-evidence-based-medicine-levels-evidencemarch-2009].

\section{EUS-guided celiac plexus neurolysis/block $\nabla$}

Background

Celiac plexus neurolysis (CPN) and celiac plexus block (CPB) are reported to offer both temporary and long-lasting pain relief, thus reducing opioid use in intra-abdominal malignancy and chronic pancreatitis [3-7].

Injection of bupivacaine with alcohol, phenol or triamcinolone into the celiac plexus disrupts signal transmission to the spinal cord and the central nervous system, theoretically interfering with pain perception. Several techniques have been used, including a percutaneous posterior or anterior access approach.

In 1996, the first case series of endoscopic ultrasound (EUS)-guided CPN was reported [8]. The anatomical location of the celiac plexus around the origin of the celiac trunk and the superior me- 
senteric artery allows the EUS-guided technique to provide nearfield, real-time visualization with a resultant potentially safer, faster and technically easier approach than percutaneous techniques. Moreover, celiac ganglia visualization by EUS in approximately $80 \%$ of cases [9-12] allows direct injection [13].

\section{Technique}

Both linear and forward-view echo-endoscopes may be used for EUS-guided CPN and CPB $[8,14]$. Color and power Doppler techniques allow easy identification of vascular structures (in order to avoid inadvertent intravascular injection). Combining neurolysis or block with other EUS-guided procedures reduces patient discomfort and improves cost effectiveness.

EUS-guided CPN and CPB techniques are identical. The only differences are with respect to clinical indications and the materials injected. EUS-guided CPN has been used in patients with pancreatic cancer and chronic pancreatitis by injecting bupivacaine and ethanol, while EUS-guided CPB has been used in patients with chronic pancreatitis by injecting bupivacaine with or without triamcinolone.

Briefly, the procedure is preceded by a preliminary intravenous infusion of $500-1000 \mathrm{cc}$ of saline solution to prevent orthostatic hypotension. Antibiotic prophylaxis is also recommended, in particular for CPB [15]. With EUS visualization, the needle is introduced in the space between the aorta and the celiac trunk origin and flushed with $3 \mathrm{cc}$ saline, followed by aspiration to ascertain inadvertent vessel penetration. Subsequently, for neurolysis, $10 \mathrm{ml}$ of $0.25 \%$ bupivacaine is injected followed by $10-20 \mathrm{ml}$ of $95 \%-98 \%$ ethanol. For CPB, either bupivacaine alone or bupivacaine followed by $80 \mathrm{mg}$ of triamcinolone is used. Finally, the needle is flushed with 3 cc of saline and removed [3, 16-19]. Standard aspiration needles (19 gauge (G), 22G, 25G) as well as a special 20G injection needle may be used [20]. Preliminary reports have described the effective use of phenol instead of alcohol in patients intolerant to alcohol [21] and the insertion of radioactive seeds $[22,23]$.

\section{EUS-guided celiac plexus neurolysis in patients with pancreatic and upper gastrointestinal malignancy Comparison with standard analgesic treatment}

EUS-guided CPN was demonstrated to be safe and effective in alleviating refractory pain due to pancreatic cancer. 8 studies (283 patients) indicated $80 \%$ of patients experienced pain relief [24]. A 5-study meta-analysis (119 patients) demonstrated the efficacy of EUS-guided CPN in $72.5 \%$ of cases [25]. In a randomized controlled trial (RCT), 96 patients with advanced pancreatic cancer were randomly assigned to early EUS-guided CPN or conventional pain management, with greater pain relief observed in the early EUS-guided CPN group at three months as compared to the conventional management group [26].

A Cochrane Review compared opioids and EUS-guided CPN. EUSguided CPN reduced pain at 4 and 8 weeks (visual analog score -0.42 and -0.44 , respectively) and significantly reduced opioid consumption [4]. A meta-analysis including patients with upper gastrointestinal cancer (5 studies, $\mathrm{n}=209$ ) showed similar findings [5]. Overall, EUS-guided CPN is more effective than conventional pain management in patients with pancreatic and upper gastrointestinal cancer.
Recommendation 1

EUS-guided CPN combined with standard analgesic treatment is superior to analgesic treatment alone in reducing pain in patients with pancreatic and upper gastrointestinal cancer (LoE 1b, GoR B). Strong consensus (100\%)

\section{Single central injection vs. bilateral injections}

Results from a retrospective single-center study ( $n=160,45 \%$ EUS-guided CPN, 55\% EUS-guided CPB) favored bilateral injections to a single central injection as the only predictor of $>50 \%$ 7-day pain reduction [27]. Sub-group analysis in the meta-analysis of Puli et al. showed pain relief in $84 \%$ of patients receiving bilateral injections vs. $46 \%$ of patients receiving central injection [24]. A study of 50 patients with pancreatic cancer randomized to receive single or bilateral injections of alcohol did not observe any difference in the onset or duration of pain relief [28]. Similar findings were reported in a retrospective study with no difference between central and bilateral techniques in the median pain reduction from baseline to 4 weeks post-procedure [29]. The assumption is that there is no difference between central vs. bilateral injections in EUS-guided CPN.

\section{Direct celiac ganglia neurolysis}

Visualization of the ganglia is possible in approximately $80 \%$ of patients [9-12], and when this occurs, direct injection of alcohol into the ganglia rather than random injection into the space between the aorta and the celiac trunk can be performed [13]. In a retrospective analysis of pancreatic malignancy (64 patients), direct injection of the ganglia was the best predictor of response to EUS-guided CPN. Patients with visible ganglia were $>15$ times more likely to respond [30]. In 34 patients with upper gastrointestinal cancer randomly assigned to either EUS-guided direct celiac ganglia neurolysis (CGN) or standard EUS-guided CPN, a higher complete response rate was observed with EUS-guided CGN (50\% vs. $18 \%$ ) [31]. In a retrospective study (41 patients), the CGN group experienced greater pain relief within 3 months after injection, a lower treatment failure rate, and faster onset and longer duration of pain relief than the CPN group [32].

\section{Other technical aspects}

Direct malignant invasion of the celiac ganglia and distribution of alcohol solely to the left side of the celiac trunk may preclude a positive response to EUS-guided CPN [32]. In patients with advanced abdominal cancer, a broader distribution of injected alcohol between the celiac trunk and the superior mesenteric artery (EUS-guided broad plexus neurolysis, BPN) using a 25G needle provides a better analgesic effect than standard EUS-guided CPN [33]. The injected volume of alcohol does not have an influence. In patients with pancreatic cancer, EUS-guided CPN using either $10 \mathrm{ml}$ or $20 \mathrm{ml}$ of absolute alcohol had similar efficacy and safety [34]. Performing EUS-guided CPN in patients with non-resectable pancreatic cancer early after diagnosis may provide better pain relief than late salvage therapy [26, 35].

There are no studies comparing percutaneous and EUS-guided CPN. A meta-analysis from 9 RCTs (5 comparing CPN with standard analgesic treatment) in patients with pancreatic and upper gastrointestinal cancer showed percutaneously guided CPN was effective in terms of pain relief and reduced opioid consumption [5]. 


\section{Recommendation 2}

The injection technique (central vs. bilateral) has no significant influence on the efficacy and safety of EUS-guided CPN and CPB (LoE 1b, GoR B). Strong consensus (100\%)

\section{Recommendation 3}

In patients with visible ganglia, EUS-guided celiac ganglia neurolysis (CGN) should be preferred to conventional EUSguided CPN as it provides greater pain relief (LoE 1b, GoR B). Strong consensus (100\%)

\section{Recommendation 4}

In patients with painful non-resectable pancreatic and upper gastrointestinal cancer, EUS-guided CPN should be considered early in the course of the disease (LoE $2 b$, GoR C). Strong consensus (100\%)

\section{EUS-guided celiac plexus block in patients with chronic pancreatitis}

Two systematic reviews reported on the efficacy of steroid-based EUS-guided CPB in patients with refractory pain due to chronic pancreatitis (6 studies, 221 patients; 9 studies, 376 patients) showing a satisfactory reduction of abdominal pain in $52 \%$ [25] and $60 \%$ [24] of the patients, respectively. One of the two metaanalyses also included a group of patients treated with alcohol injection (EUS-guided CPN) [24]. Pain relief was mostly transient lasting up to 3 months [25]. The largest prospective cohort $(n=90)$ reported the proportion of patients responding to EUSguided CPB decreased from $55 \%$ immediately after treatment to $10 \%$ at 24 weeks [15]. A large retrospective study $(n=248)$ showed that repeat EUS-guided CPB in patients with chronic pancreatitis is safe. Pain relief after the first procedure was observed in $76 \%$ of patients and was significantly associated with response to subsequent sessions [36].

With suboptimal pain control obtained with EUS-guided CPB in chronic pancreatitis and documented serious infectious episodes, injection of triamcinolone during EUS-guided CPB has been questioned. To evaluate the effect of the addition of triamcinolone to bupivacaine, 40 patients were randomized to receive either bupivacaine alone or bupivacaine and triamcinolone. There was no significant difference in pain control between the two groups (14\% vs. $16 \%$ for controls), and the trial was stopped [37], with no advantage of adding triamcinolone to bupivacaine for EUS-guided CPB. Preliminary results of an RCT reported a significant advantage of EUS-guided CPB using bupivacaine and triamcinolone vs. a sham procedure in terms of pain reduction. However, morphine use was similar between the two groups [38].

Leblanc et al. randomized 50 patients with chronic pancreatitis to receive one central or two bilateral injections of bupivacaine and triamcinolone without observing any difference in the duration of pain relief or onset of pain. $62 \%$ of the patients responded to EUS-guided CPB, with an average of 38 days of pain relief among responders [39].

In conclusion, EUS-guided CPB is only moderately effective in pain control in patients with chronic pancreatitis, independent of combining bupivacaine and triamcinolone, and independent of the use of either the central or bilateral injection technique. Repeat proce- dures in the same patients seem to be safe and may prolong pain relief in patients responding to a first EUS-guided CPB.

\section{Recommendation 5}

EUS-guided CPB induces moderate pain improvement compared to analgesic drugs only ( $\operatorname{LoE} 2 \mathrm{a}$, GoR B). Strong consensus $(100 \%)$

An RCT comparing the safety and efficacy of EUS-guided vs. computed tomography-guided CPB in chronic pancreatitis showed that the former was significantly more effective than the latter in short-term ( $50 \%$ vs. $25 \%$ at 4 weeks) and long-term pain control (30\% vs. $12 \%$ at the end of follow-up) [40].

Another RCT comparing EUS-guided vs. percutaneous fluoroscopyguided CPB with bupivacaine and triamcinolone demonstrated improvement in pain scores (visual analog score) in $70 \%$ of cases in the EUS group vs. $30 \%$ of cases in the percutaneous group [41]. In conclusion, EUS-guided CPB provides better pain control than the percutaneous techniques.

\section{Recommendation 6}

For chronic pancreatitis, percutaneous $\mathrm{CPB}$ has inferior efficacy compared with EUS-guided $\mathrm{CPB}$, and therefore it is not recommended for use in clinical practice (LoE 1b, GoR A). Strong consensus $(100 \%)$

\section{Adverse events}

Adverse events related to EUS-guided CPN and CPB occur in up to $30 \%$ of cases, most commonly diarrhea $(7 \%)$, increase in abdominal pain (2\%-4\%) and hypotension (4\%). All symptoms are usually mild (grade I-II) and self-limiting [5, 42, 43]. A review of 20 studies (1142 patients) of EUS-guided CPN or CPB described adverse events in $7 \%$ of 481 EUS-guided CPB procedures and $21 \%$ of 661 EUS-guided CPN interventions. Minor adverse events were observed more often after EUS-guided CPN as compared to CPB (21\% vs. $7 \%$ ) [43]. Repeat EUS-guided CPN and CPB are not associated with a higher rate of adverse events [44, 45].

Serious adverse events related to EUS-guided CPN $(0.2 \%)$ and CPB $(0.6 \%)$ are reported and include bleeding, retroperitoneal abscess (in EUS-guided $\mathrm{CPB}$ ), abdominal ischemia, permanent paralysis and death (2 cases) [43].

The risk of serious morbidity and mortality should be weighed against expected benefits particularly in patients without underlying malignancy (e.g. chronic pancreatitis).

\section{Recommendation 7}

The safety profile of EUS-guided CPN and CPB is favorable. However, due to some serious adverse events that have been reported with EUS-guided CPN, its use in patients with benign conditions should be considered with caution (LoE 4, GoR C). Broad agreement (92\%)

\section{Recommendation 8}

Antibiotic prophylaxis should be considered before EUS-guided CPB when steroids are used ( $\operatorname{LoE} 5$, GoR C). Strong consensus $(100 \%)$ 


\section{EUS-guided vascular interventions}

$\nabla$

\section{Background}

EUS is a valuable tool for the diagnosis of portal hypertension [46 - 50]. Varices are visualized as compressible anechoic tubular structures within the submucosa of the esophagus, stomach, and intestine, with color or power Doppler signal. EUS may be useful to guide endoscopic treatment of esophageal and gastric varices by identifying peri-intestinal collaterals and perforating veins, or documenting inadequate obliteration of varices and collaterals [46, 51-53]. EUS can identify rare causes of gastrointestinal bleeding, e.g. arterial pseudoaneurysm [54-58] and Dieulafoy lesions [59].

\section{Treatment of bleeding in patients with portal hypertension}

EUS-guided management of upper gastrointestinal varices and bleeding has benefits over endoscopy by identifying perforating and/or collateral veins, thus allowing precise delivery of sclerosing agents, glue, or coils [60]. EUS-guided cyanoacrylate obliteration of perforating veins in 40 consecutive patients with gastric varices was reported. In all 13 patients with active bleeding, immediate cessation of hemorrhage was achieved, but $15 \%$ of patients needed an alternative rescue therapy due to recurrent bleeding [61]. An RCT compared standard endoscopic sclerotherapy of esophageal varices with EUS-guided sclerotherapy of collateral veins. Recurrent bleeding in the EUS group was less frequent and occurred later [62]. Comparable results have been reported in a case series [63]. A comparison of EUS-guided variceal obliteration to rubber-band ligation has not been reported. The efficacy of EUS-guided coil vs. cyanoacrylate therapy has been compared in consecutive patients with gastric varices in a non-randomized study where EUS-guided coil application required fewer endoscopies and reported fewer adverse events compared with EUS-guided cyanoacrylate injection [64]. Experience from this study and case series indicates that the EUS-guided technique is effective in reducing the amount of glue injected but does not completely eliminate the risk of glue embolization. In patients with acute bleeding, the EUS approach is problematic as the necessary skills are not widely available. Technical problems include the side viewing endoscopic optic and the relatively small working channel of the majority of echo-endoscopes [61, $64-68$ ]. Successful treatment of severe bleeding from rectal and duodenal varices has been described in case reports [69-75].

\section{Treatment of non-variceal bleeding}

Case series and single cases report successful EUS-guided treatment of non-variceal bleeding from peptic ulcer disease, Dieulafoy lesions, and gastrointestinal tumors after unsuccessful standard endoscopic treatment. Recurrent duodenal ulcer bleeding was successfully treated with EUS-guided cyanoacrylate injection in a vessel just below the ulcer $[60,76]$. Case studies report successful treatment of Dieulafoy lesions with EUS-guided sclerotherapy [59, 76, 77]. In 17 patients with ineffective or unsuitable standard treatment of non-variceal bleeding, EUS-guided hemostatic interventions had a long-term success rate of $88 \%$ [78].

Pseudoaneurysm therapy and other vascular procedures Single reports demonstrate successful EUS-guided injection treatment with the injection of cyanoacrylate, vascular coils, absolute alcohol, or $500 \mathrm{IU}$ thrombin directly into pseudoaneu- rysms of the splenic and superior mesenteric artery where conventional therapy has failed [60, 76, 78 - 84].

EUS-guided vascular procedures are shown to be possible in animal experiments: EUS-guided transhepatic angiography of visceral arteries and the portal venous system [85, 86], EUS-guided embolization of the portal venous system [85-89], and EUSguided creation of a portosystemic shunt [90].

\section{Recommendation 9}

EUS-guided treatment may be considered as a salvage therapy for variceal bleeding when standard treatment fails or is not feasible (LoE 4, GoR C). Strong consensus (100\%)

Recommendation 10

EUS-guided treatment may be considered in life-threatening non-variceal gastrointestinal bleeding after failure of standard treatment (LoE 4, GoR C). Strong consensus (100\%)

\section{EUS-guided drainage of pancreatic fluid collections}

$\nabla$

\section{Background}

Pancreatic and peri-pancreatic fluid collections (PFC) develop as a consequence of acute pancreatitis and resurgences of chronic pancreatitis, pancreatobiliary endoscopic interventions, endoscopic pancreatic surgery and pancreatic trauma. According to the etiology, time interval from the precipitating event, location, and morphological features, the revised Atlanta classification categorizes PFC as acute peri-pancreatic fluid collection (APFC), pancreatic pseudocyst (PPC), acute necrotic collection (ANC) and walled-off pancreatic necrosis (WOPN) ( $\bullet$ Table 1 ) [91].

Treatment methods include percutaneous drainage, endoscopic transpapillary drainage, endoscopic transmural drainage \pm EUS

Table 1 Revised Atlanta classification (2012) of pancreatic/peri-pancreatic fluid collections [91].

\begin{tabular}{|c|c|c|c|}
\hline $\begin{array}{l}\text { type of pancreatic } \\
\text { or peripancreatic } \\
\text { fluid collection }\end{array}$ & etiology & $\begin{array}{l}\text { cap- } \\
\text { sule }\end{array}$ & specific features \\
\hline $\begin{array}{l}\text { acute peripancrea- } \\
\text { tic fluid collection, } \\
\text { APFC }\end{array}$ & $\begin{array}{l}\leq 4 \text { weeks after } \\
\text { onset of acute } \\
\text { interstitial- } \\
\text { edematous } \\
\text { pancreatitis }\end{array}$ & - & $\begin{array}{l}\text { homogeneous, } \\
\text { liquid, infection } \\
+/-, \text { no features } \\
\text { of a pseudocyst, } \\
\text { usually sponta- } \\
\text { neous resolution }\end{array}$ \\
\hline $\begin{array}{l}\text { pancreatic pseudo- } \\
\text { cyst, PPC }\end{array}$ & $\begin{array}{l}>4 \text { weeks after } \\
\text { onset of acute } \\
\text { interstitial- } \\
\text { edematous } \\
\text { pancreatitis }\end{array}$ & + & $\begin{array}{l}\text { round/oval, liquid, } \\
\text { no non-liquid con- } \\
\text { tents, persistent }\end{array}$ \\
\hline $\begin{array}{l}\text { acute necrotic col- } \\
\text { lection, ANC }\end{array}$ & $\begin{array}{l}\text { acute necrotiz- } \\
\text { ing pancrea- } \\
\text { titis }\end{array}$ & - & $\begin{array}{l}\text { heterogeneous, } \\
\text { liquid and necrotic } \\
\text { contents, usually } \\
\text { spontaneous reso- } \\
\text { lution }\end{array}$ \\
\hline $\begin{array}{l}\text { walled-off pancre- } \\
\text { atic necrosis, } \\
\text { WOPN }\end{array}$ & $\begin{array}{l}>4 \text { weeks after } \\
\text { onset of necro- } \\
\text { tizing pancrea- } \\
\text { titis }\end{array}$ & + & $\begin{array}{l}\text { heterogeneous, } \\
\text { liquid and necrotic } \\
\text { contents, infec- } \\
\text { tion +/- }\end{array}$ \\
\hline
\end{tabular}


guidance), and surgical drainage either by open or laparoscopic surgery [92-96].

Technical success is defined by the ability to access and drain the PFC whereas treatment success comprises clinical and radiologic improvement. Clinical success is the resolution of symptoms that prompted intervention. Treatment success is related to the type of PFC. Higher success rates are described for pseudocysts and abscesses compared to pancreatic necrosis $[97,98]$. Intervention is mainly indicated for infected necrosis, less often for symptomatic sterile necrosis, and should ideally be delayed as long as possible ( $\geq 4$ weeks after the onset) for better necrotic tissue demarcation and liquefaction $[99,100]$. With infected pancreatic necrosis, there is a significant association between the development of organ failure, need for intensive care treatment and in-hospital mortality $[91,93,101]$. The role of EUS in the evaluation of acute pancreatitis is primarily reserved for assessing and/or confirming choledocholithiasis with subsequent stone removal by endoscopic retrograde cholangiopancreatography (ERCP), for identifying anatomic abnormalities (pancreas divisum) or to rule out malignancy [102 - 107]. Prior to any drainage procedure, differentiation of PPC from cystic neoplasms, detection of solid debris within PFC, and the identification of visceral pseudoaneurysms and portosystemic collaterals are mandatory [108-112].

\section{Treatment indications}

APFC and ANC regress spontaneously in the majority of cases without intervention. The rate of regression is influenced by the size and time from diagnosis. Five studies have documented that the majority of asymptomatic pseudocysts $(<4 \mathrm{~cm})$ regress spontaneously and require no treatment. In a study of 91 patients, a pseudocyst diameter $\geq 6 \mathrm{~cm}$ or persistence $>6$ months was the only independent predictor of the need for drainage [113].

The rate of spontaneous regression is lower in chronic PPC, reported at $<10 \%$. Other factors that make spontaneous regression unlikely include: presence of multiple cysts, location in the pancreatic, wall thickness $>1 \mathrm{~cm}$, absence of communication with the Wirsung duct, proximal ductal stenosis, interruption of pancreatic duct, biliary or traumatic etiology, or an increase in size on follow-up [114]. A multicenter study reported a delayed interventional approach had a lower mortality rate, with a conservative approach being possible in $62 \%$ of acute necrotic collections [99]. Drainage is considered if collections become symptomatic or infected. Infection is more common in necrotic collections, demonstrated by air within the collection on CT imaging. In the presence of infection, the prognosis worsens considerably [101, 115 -118]. Infected collections may be sampled by EUS-guided fine needle aspiration (EUS-FNA) to obtain microbial analysis, which guides antibiotic treatment [119, 120]. With a sterile collection, luminal or biliary extrinsic compression and persistent severe abdominal pain are indications for drainage [100, $121,122]$.

\section{Recommendation 11}

The decision to drain a pancreatic fluid collection (PFC) depends on clinical symptoms, condition of the patient, change in size over time, time from onset of symptoms, and infection (LoE 2b, GoR B). Strong consensus (100\%)

\section{Recommendation 12}

Before performing drainage of a suspected PFC, diagnostic characterization must be performed to avoid misdiagnosis and to guide proper management decisions. Therefore, both thorough clinical history and appropriate imaging should be performed to exclude cystic pancreatic neoplasms (LoE $2 b$, GoR C). Strong consensus (100\%)

\section{Recommendation 13}

While asymptomatic pancreatic and/or extra-pancreatic fluid collections do not warrant intervention regardless of size, location, and/or extension, drainage should be performed in case of persistent abdominal complaints or complicated disease (LoE 4, GoR C). Strong consensus (100\%)

\section{Recommendation 14}

Transmural drainage of infected pancreatic necrosis should be delayed until demarcation has been accomplished (LoE 2b; GoR B). In clinically unstable patients despite appropriate intensive care, immediate drainage is recommended (LoE 5, GoR D). Strong consensus (100\%)

\section{EUS-guided drainage technique}

EUS-guided drainage is suitable for pancreatic collections abutting the gastric or duodenal wall where a transgastric or transduodenal approach is feasible. Two types of linear echoendoscopes are available for EUS-guided PFC drainage: i) a traditional side-viewing longitudinal echoendoscope and ii) a forwardviewing echoendoscope specifically made for interventional procedures. No difference in outcome between the echoendoscopes has been documented [123].

EUS-guided drainage in a stepwise manner begins with initial visualization of the PFC using a linear echoendoscope ( $\bullet$ Fig. 1 ). EUS normally allows visualization of the entire cavity with contents, assesses wall maturity, measures the collection to luminal wall distance and identifies vessels (specifically: portovenous collaterals) along the puncture tract. EUS-guided drainage is performed either by a multistep or by a one-step procedure, usually guided by fluoroscopy. The multi-step technique is most frequently performed where the fluid collection is punctured with a 19G needle or a fistulotome/cystotome [18, 124, 125]. EUSguided PFC drainage is also feasible without fluoroscopic guidance $[126,127]$. A hydrophilic guidewire is then introduced via the needle followed by tract dilatation using either a tapered dilator catheter, dilating balloon or the fistulotome/cystotome itself $[18,124,125]$. When multiple stents or a stent and a nasocystic irrigation tube are to be positioned, a double guidewire approach where two guidewires are simultaneously inserted via first puncture and penetration with the fistulotome/cystotome is reasonable [128-132]. With WOPN, the tract is dilated to up to $20 \mathrm{~mm}$ at the first endoscopy, followed, when indicated, with debridement of the intracavitary solid material by introducing a forward-viewing gastroscope across the gastric or duodenal wall into the cavity. The necrotic pancreatic tissue can be removed using a combination of balloons, snares, water jets, and baskets. All possible devitalized tissue is removed on each occasion, and placed in the stomach or duodenum. To prevent bleeding, aggressive mechanical fragmentation of necrotic tissue should be 


\section{Pseudocyst}

Alternative treatment strategy: in case of ductal disruption or association: trans-papillary endoscopic drainage

EUS-guided access (19-gauge needle, alternatively diathermic device)

Direct one-step introduction of the fistulotome/cystotome or graded dilatation of the access tract according to the intended stent size Insertion of drains (plastic stents, cSEMS)

\section{Consider nasocysticirrigation tube}

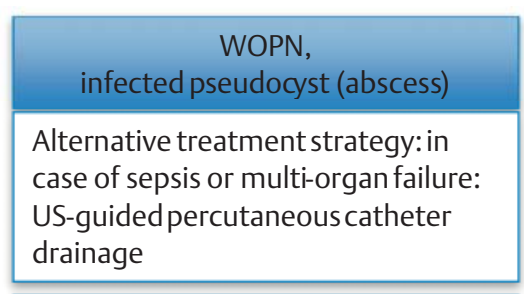

EUS-guided access (19-gauge needle, alternatively diathermic device), optionally multiple gateway access

Direct one-step introduction of the fistulotome/cystotome or graded dilatation of the access tract according to the intended stent size

Insertion of drains (plastic stents, cSEMS), preferably large-caliber cSEMS and/or multiple plastic stents) and irrigation tubes

In case of large collections with extension to the pericolic gutter, large amount of necrotic debris: consider combined transmural and percutaneous approach

Permanent or intermittentirrigation

In case of large necrosis: consider repeating direct endoscopic debridement
Fig. 1 Algorithm of EUS-guided drainage of pancreatic fluid collections (PFC). avoided. Removal of loose necrotic tissue with additional cavity saline irrigation is sufficient. Stents must be left in place at procedure conclusion, to allow the fistula tract to remain patent [18, $124,125,133,134]$. It is advisable that these maneuvers are performed under $\mathrm{CO}_{2}$ insufflation only.

A variety of stents have been used to maintain patency of the fistulous tract between the gut lumen and the PFC: single plastic stents (straight or double pigtail), multiple plastic stents, nasocystic drainage catheters, enteral metal stents and biliary metal stents [95, 125, 135-139]. Some studies have also described a combination of modalities, e.g. plastic stents in combination with nasocystic drainage catheters $[128,140,141]$ or double pigtail stents axially placed through a metal stent. Up to now, there is no clear evidence to suggest that expandable metal stents are superior to plastic stents or different plastic stents offer a techni- cal advantage [124, 134, 135, 142 - 144]. Expandable metal stents have a shorter procedure time as documented in an RCT [145] and a meta-analysis [146]. PFC drainage by self-expandable metal stents improved the clinical success rate and decreased the adverse event rate compared with PFC drainage by plastic stents [138]. Novel lumen-apposing self-expandable metal stents and other dedicated stents have been developed that can be deployed in a single step for PFC drainage [136, 137, 145, 147 - 162].

\section{Recommendation 15}

EUS-guided transmural PFC drainage may be performed with or without fluoroscopic guidance (LoE 4, GoR C). Strong consensus $(100 \%)$ 
Recommendation 16

Plastic stents and/or covered self-expandable metal stents may be used for transmural EUS-guided PFC drainage, with or without an additional irrigation tube (LoE 5, GoR D). Strong consensus (100\%)

\section{Outcome of EUS-guided drainage}

\section{Pancreatic fluid collections}

The prevalence of PPC ranges from $6-18.5 \%$ after acute pancreatitis, and the prevalence in chronic pancreatitis is $20-40 \%$ [114]. EUS-guided treatment provides comparable efficacy to surgical drainage with a shorter hospital stay and lower cost [163-165]. In 81 patients with symptomatic PPC, the clinical success rate of endoscopic internal drainage was comparable to percutaneous drainage, but percutaneous drainage was associated with a significantly higher rate of re-intervention, a longer hospital stay, and an increase in follow-up imaging [96]. A percutaneous procedure requires an external drain for an extended period of time, possibly responsible for the development of pancreaticocutaneous fistulas especially in ductal disruption [114, 166, 167]. Endoscopic PFC drainage may be performed either during ERCP with drainage through the main papilla of Vater or via a transmural route, either via the duodenum or the stomach, exceptionally through the esophagus. There are no comparative or randomized studies regarding the preferred method of drainage. A case series and guidelines based on expert opinion are available $[122,168-170]$ and indicate that trans-papillary drainage is preferable to EUS-guided transmural drainage as the initial procedure if ERCP demonstrates a disrupted pancreatic duct. Most studies with EUS-guided drainage lack a description of whether patients have undergone ERCP prior to EUS-guided drainage. In 116 patients, 15 of whom underwent trans-papillary drainage, 60 transmural drainage and 41 both methods, successful drainage was achieved in $88 \%$ of cases. There was no difference in success between the two methods [170].

Pooled data from 55 studies $(\mathrm{n}=1867$ ) demonstrate mean technical and clinical success rates of $97 \%(83-100 \%)$ and $90 \%$ (69$100 \%)$, respectively, for EUS-guided transmural drainage of PPC, with a mean recurrence rate of $8 \%(0-23 \%)$ [171]. There is limited data on abscess drainage with treatment success rates ranging from $80 \%$ to $98 \%$, comparable to that of non-infected PPC $[172,173]$. EUS-guided drainage of PPC has a higher technical success rate when compared to conventional transmural endoscopic drainage. However, in PPC with clear bulging there is no difference in clinical outcome [174-176]. EUS-guided drainage is the preferred modality when there is no visible luminal bulge or when there is a clinical suspicion of portal hypertension and collaterals or in coagulopathy [175-179]. Transmural cystoduodenostomy has a higher long-term success rate than cystogastrostomy [122].

\section{Recommendation 17}

The particular drainage technique for PPC should be chosen in consideration of location, infection and/or portal hypertension (LoE 5, GoR D). Strong consensus (100\%)

\section{Recommendation 18}

EUS-guidance should be preferred for transmural drainage of PPC and other PFC (e.g. WOPN), in particular in the absence of luminal bulging and in the case of portal hypertension (LoE 1b, GoR B). Strong consensus (100\%)

\section{Walled-off pancreatic necrosis}

Surgical management of WOPN may be performed either by an open surgical procedure or by a laparoscopic approach. Traditionally the treatment of necrotizing pancreatitis with infected necrotic tissue is open necrosectomy with complete removal of the infected necrotic tissue. However, this is associated with high morbidity and mortality (11\% to $39 \%$ ) and with a risk of long-term pancreatic insufficiency. A conservative approach is possible in $62 \%$ of cases, with primarily percutaneous catheter drainage in infected necrosis associated with a lower mortality than surgical necrosectomy $[99,180]$. When percutaneous drainage alone was performed in 384 patients with WOPN, no additional surgical necrosectomy was required in 214 (55.7\%) patients, with a mortality rate of $17 \%$ [181].

Over the last 10 years endoscopic drainage has become important in the treatment of WOPN with a comparable efficacy to surgical drainage with lower costs and a shorter hospital stay [182]. Surgical drainage is reserved for endoscopic failures, recurrence following successful endoscopic drainage or those not meeting criteria for endoscopic or percutaneous drainage.

The clinical outcomes by EUS-guided drainage of WOPN are generally inferior to PPC. The treatment success rate was $94 \%$ for sterile and infected PPC versus $63 \%$ for WOPN $[97,183]$. An analysis comparing the efficacy of transmural drainage alone vs. transmural drainage combined with endoscopic debridement in patients with symptomatic WOPN [184] found complete resolution of WOPN occurred significantly more often with endoscopic debridement compared with transmural drainage alone $(88 \%$ versus $45 \%$ ) [184]. Mean clinical success rates of $81 \%$ to $88 \%$ and mean recurrence rates of $7 \%$ to $11 \%$ have been reported in systematic reviews concerning an aggressive endoscopic approach using transmural drainage followed by endoscopic necrosectomy [171, 185, 186]. Combining all available non-surgical drainage techniques (trans-papillary, transmural, percutaneous) gives an overall success rate of up to $94 \%$ [173].

As the necrotic component in the collection increases, the success rate progressively decreases unless aggressive endoscopic necrosectomy or concomitant percutaneous drainage is also used, with the need for surgery being more common. A meta-analysis documented a median of 4.09 drainage procedures to be necessary for effective transmural necrosectomy of WOPN [185]. A study in 43 patients with symptomatic WOPN treated by endoscopic drainage [110] found the number of sessions was dependent on the size of the collection and the amount of solid debris. Patients with $<10 \%$ necrotic debris $(n=6)$ only needed a single session of endoscopic drainage, whereas patients with $10-40 \%$ solid debris $(n=33)$ needed $\geq 2$ sessions. Patients with $>40 \%$ solid debris $(n=4)$ either needed direct endoscopic debridement or surgical necrosectomy. The extent of necrosis correlated significantly with the type of treatment received by the patient [110].

The Dutch pancreatitis study group has shown that, in necrotizing pancreatitis and secondary infection, a step-up approach consisting of percutaneous drainage followed by minimally invasive retroperitoneal necrosectomy is a better treatment strategy 
than open necrosectomy $[93,187]$. New-onset multiple-organ failure occurred less often in patients assigned to the step-up approach than in those assigned to open necrosectomy (12\% vs. $40 \%$ ) [188], with these results being substantiated by other studies $[93,94,173,181,187,189$ - 195]. EUS-guided creation of multiple transluminal gateways for WOPN achieves successful response in $92 \%$ of cases [140]. Analysis of the factors impacting the results of the endoscopic treatment of WOPN found multiple transluminal gateway treatment was more successful than conventional single gateway access ( $94 \%$ vs. $62 \%$ ) [196]. The optimal strategy in WOPN is a "tailored" minimally invasive approach, based on the collection size, location and stepwise response to intervention $[98,188,197]$.

\section{Recommendation 19}

The number of repeat endoscopic treatments depends on the clinical condition of the patient, the size of the PFC and the amount of solid debris (LoE 2b, GoR B). Strong consensus $(100 \%)$

\section{Recommendation 20}

Treatment of WOPN including EUS-guided and percutaneous ultrasound-guided techniques should be tailored to the general clinical condition of the patient and to the characteristics of each particular collection (LoE 1b, GoR B). Strong consensus $(100 \%)$

\section{Recommendation 21}

EUS-guided techniques should be used to create a long-term stable large transmural endoscopic access to WOPN and/or multiple internal gateways to facilitate aggressive irrigation, drainage and/or endoscopic debridement (LoE 2b, GoR B). Strong consensus (100\%)

\section{Recommendation 22}

A combination of transmural EUS-guided and percutaneous image-guided approaches should be considered as an alternative to surgery in refractory cases (LoE $2 b$, GoR B). Strong consensus $(100 \%)$

\section{Timing of stent removal}

There are conflicting recommendations as to the optimal time for stent removal, ranging from a few weeks to indefinitely [172, 196, 198-200]. Early stent removal may lead to recurrence of the PFC. Removal of stents at 4 weeks following endoscopic treatment of infected PPC and WOPN resulted in an optimal success rate [172]. A prospective cohort study in 47 patients in whom EUS-guided drainage of symptomatic PPC was performed showed a low long-term recurrence rate $(4.7 \%)$ after stent removal at 3 weeks, if trans-papillary stenting was performed in patients with pancreatic ductal leak. Pancreatic ductal leak or disconnection was significantly associated with PPC resolution failure at 3 weeks [201]. Results of several prospective and retrospective studies suggest long-term transmural stenting in WOPN, in particular in patients with pancreatic duct leaks or disruption. In 30 patients with disconnected pancreatic duct syndrome who underwent transmural drainage of WOPN with long-term indwelling stents (mean 20.4 months, range 3-38 months), 5 patients had spontaneous migration of the stents (one followed by PFC recurrence), and the remaining 25 patients had no recurrence of symptomatic PFC [199]. In a retrospective study evaluating factors impacting treatment success in the endoscopic management of WOPN in patients with WOPN and disconnected pancreatic duct, transmural stents were left in place indefinitely. PFC recurrence was significantly lower in the patients with indwelling transmural stents than in patients in whom the stents were removed (0\% vs. $21 \%$ ) [196]. The effect of two different schedules for stent removal was evaluated in an RCT [200]. In 15 patients, stent retrieval took place after two months, and in 13 patients stent retrieval was scheduled for 12 months post-insertion. In 5/15 patients with stent removal after two months, a recurrence was seen, while none of the 13 patients with stent removal at 12 months experienced a recurrence. Stent clogging or infection was not reported in any of the 13 patients with an extended drainage period [200].

\section{Recommendation 23}

To avoid infection and recurrence, transmural stents should be left in place until resolution of the collection is achieved (LoE 2b, GoR C). Strong consensus (100\%)

\section{Adverse events}

Adverse events, most frequently bleeding (2\%), perforation (1.6\%), secondary infection (4\%) and stent migration, range from $0-26 \%$ $[97,146,202,203]$. Few procedure-related mortality cases mainly due to bleeding have been reported $[1,8,9]$. Severe bleeding events occurred following erosion of the splenic and gastroduodenal artery [183] or following rupture of a visceral pseudoaneurysm $[170,173,204]$. Vascular derangements subsequent to acute pancreatitis must be excluded before performing transmural drainage [205]. Secondary infection arises from contamination of an incompletely drained $\mathrm{PFC}$, from premature stent occlusion, stent dislocation, or uneven collapse [168, 198, 206 - 208]. Dislocation of transmural plastic stents occurs in approximately $5 \%$ of cases [43] but was also observed with specially designed covered metal stents [137]. The risk of perforation increases when the pseudocyst wall is poorly defined or is $>1 \mathrm{~cm}$ from the intestinal lumen. Surgery is required in up to $5-11 \%$ of cases, with most adverse events managed conservatively, normally by an interventional radiologist or by endoscopy [10]. Pneumothorax, air embolism [189-191, 209] and intra-abdominal abscess are rarely reported. In WOPN compared to PPC, procedure complexity and a serious underlying clinical condition increase the morbidity and mortality $[43,185,210]$. Varadarajulu et al. reported a significantly higher adverse event rate in cases of pancreatic necrosis (16\%) compared with PPC and abscesses [7]. A meta-analysis on endoscopic transmural treatment of WOPN ( 8 studies, $\mathrm{n}=288$ ) demonstrated adverse events in $21.3 \%$ and recurrence in $10.9 \%$ of cases. Surgery was needed for non-resolving WOPN in 13\% [185]. Another systematic review included 13 case series and one prospective study with 455 patients and found a procedure-related morbidity of $36 \%$ (bleeding: $18 \%$ ) and an overall mortality of $6 \%$ [186].

There are limited data on who should perform minimally invasive treatment including EUS-guided drainage in patients with WOPN. A consensus report from the USA suggests that management of these patients should only be performed in high-volume 
centers with specialized experience in interventional endoscopy and radiology, intensive care, and surgery [93].

\section{Recommendation 24}

Minimally invasive treatment of WOPN including EUS-guided transmural approaches should be performed in referral centers with experience in performing image-guided interventions, pancreaticobiliary endoscopic procedures, and surgical treatment (LoE 5, GoR D). Strong consensus (100\%)

\section{EUS-guided drainage of non-pancreatic fluid collections \\ $\nabla$}

\section{Background}

Normally a non-pancreatic fluid collection is managed by percutaneous or operative drainage, although EUS-guided drainage of fluid collections may be as safe and effective [211]. A systematic review of EUS-guided fluid drainage procedures of collections bordering the gastrointestinal tract (mediastinum, perihepatic (subphrenic), hepatic, pelvic, perirectal space) reported technical and clinical success rates of $99 \%$ and $92 \%$, respectively, with an overall adverse event rate of $13 \%$ [171]. Initial studies used either plastic stents or catheters. More recently, also self-expandable metallic stents have been used for abscess drainage [171].

\section{Technique}

The technique does not differ from EUS-guided PFC drainage. Mediastinal abscesses along with abdominal abscesses (hepatic, perihepatic, subphrenic and splenic) [216 - 223] can be drained by EUS guidance with either plastic or self-expandable metal stents [212 - 215]. Metallic stents may be preferred due to the decreased risk of leakage or occlusion [223]. Pelvic and prostatic collections may also be drained by EUS guidance, as an alternative to surgery or percutaneous techniques, with a reported technical success of $100 \%$, a clinical success rate of $96 \%$ and low adverse events [224-234].

Drainage routes can be transesophageal, transgastric or transcolonic (transrectal), depending on the relationship between the collection and gastrointestinal tract [235]. Other fluid collections, e.g. bilomas, hematomas or inflammatory collections, can be drained completely by EUS guidance [215, 234-237]. The technique is particularly valuable for the management of postoperative intra-abdominal fluid collections after intended curative surgery or liver transplantation [215, $234-237]$.

\section{Recommendation 25}

EUS-guided drainage of mediastinal, abdominal or pelvic nonpancreatic fluid collections might be considered a feasible and safe option in referral centers with expertise in interventional EUS (LoE 4, GoR C). Strong consensus (100\%)

\section{EUS-guided biliary and pancreatic interventions \\ $\nabla$}

\section{EUS-guided cholangiography/drainage}

Background

Endoscopic retrograde cholangiopancreatography (ERCP) is the procedure of choice in obstructive jaundice due to any form of benign or malignant disease [238, 239]. ERCP is successful in $>90 \%$ of cases, while selective trans-papillary cannulation and drainage may fail in locally advanced tumors with duodenal infiltration, high-grade biliary stricture or with altered anatomy especially from prior surgery. When ERCP is not feasible, alternative techniques are percutaneous transhepatic cholangiography and drainage (PTCD) or surgical biliary bypass [240 - 243]. PTCD is technically successful in $>90 \%$ of cases, but compared with ERCP (morbidity $6.85 \%$, mortality $0.33 \%$ [244 - 246]), has higher adverse events ( $9-33 \%$, mortality $2 \%$ ) and the disadvantage of a persistent external fistula when internal drainage fails [247255]. Surgical decompression of obstructed bile ducts is associated with an even higher frequency of adverse events ( $9-44 \%)$ and procedure-related mortality (3\%) [256 - 258].

Alternatively, EUS-guided bile duct interventions may be performed following ERCP failures. In 1996, the first cases of EUSguided transduodenal cholangiopancreatography after failed ERCP to facilitate the success of a second attempted ERCP were reported and were technically successful in $70 \%$ of patients [259]. In 2001, EUS-guided biliary drainage was performed in two steps to achieve choledochoduodenostomy [260] and as a one-step technique to place plastic stents into the common bile duct or the dilated left intrahepatic duct (choledochoduodenostomy and hepaticojejuno/gastrostomy) [261]. Moreover, EUS-guided biliary rendezvous drainage in malignant obstructive jaundice after failed ERCP has been described [262]. EUS-guided cholangiography has also been described in benign diseases with unsuccessful ERCP (e.g. failed cannulation, duodenal diverticulum, choledochal cyst, chronic pancreatitis, postsurgical stricture) [263 - 267]. In one study of EUS-guided bile duct access and drainage procedures where $81 \%$ of patients had malignant disease (pancreatic cancer, cholangiocarcinoma, metastatic disease) as a cause of biliary obstruction and $19 \%$ of patients had benign disease (choledocholithiasis, benign papillary or bile duct stenosis, stricture of hepaticojejunostomy, pancreatitis), higher success rates were observed for malignant indications (90.2 vs. $77.3 \%$ ) [267].

Common terminology for all EUS-guided diagnostic and therapeutic interventions independent of the access route into the bile ducts was introduced by a consortium of experts [268]. EUS-guided cholangiography and cholangiodrainage (ESC-D) is indicated if biliary drainage is necessary and conventional ERCP failed or is not feasible due to surgically altered anatomy of the upper gastrointestinal tract, gastric or duodenal obstruction, non-traversable obstruction of the papilla or bile duct, or the presence of anatomical variants (e.g. duodenal diverticulum) [268 - 270].

Many single-center and multicenter studies with different approaches, techniques and devices have reported technical and clinical success rates for ESC-D of $69-100 \%$ and $70-100 \%$, respectively [171, $271-273]$.

\section{ESC-D vs. PTCD}

Patients with unresectable malignant biliary obstruction and failed ERCP $(n=25)$ were randomized to PTCD or ESC-D. In both groups, the technical and clinical success rates were $100 \%$, with 
no significant difference in adverse events [274]. In a retrospective analysis of 50 patients, internal stenting was technically and clinically successful in $23 / 25$ (92\%) patients with ESC-D vs. only 12/26 (46\%) patients with PTCD. Adverse events were significantly higher in the PTCD group (46\%) compared to the ESC-D group (20\%) [275]. In another retrospective study including 73 patients who underwent ESC-D $(n=22)$ or PTCD $(n=51)$ for malignant obstruction, the technical success rate was higher in the PTCD group (100\% vs. $86 \%$ ), while the clinical success rate was similar (93\% vs. $86 \%$ ). PTCD was associated with more adverse events ( $29 \%$ vs. $18 \%)$ and a significantly higher re-intervention rate ( $80 \%$ vs. $16 \%)$ [276].

\section{ESC-D vs. ERCP}

In patients with distal bile duct obstruction and failure of selective retrograde cannulation, the EUS-guided rendezvous treatment $(n=58)$ success rate was higher compared with a historical cohort of patients $(\mathrm{n}=144)$ who underwent precut sphincterotomy (98.3\% vs. $90.3 \%$ ) without a difference in adverse events (3.4\% vs. 6.9\%) [263]. A comparison of the endoscopic placement of self-expandable metal stents using either ERCP or ESC-D for malignant distal bile duct obstruction was performed, with no statistically significant difference between ESC-D and ERCP in terms of technical success, adverse events, and mean procedure time [277].

Even with either small patient numbers or a retrospective design, studies show that the efficacy and safety of EUS-guided biliary interventions in patients with malignant distal biliary obstruction and difficult papillary access are comparable with either PTCD or ERCP.

\section{Recommendation 26}

In patients with malignant obstructive jaundice and failed ERCP, EUS-guided cholangiography drainage of the biliary tract can be considered as an alternative to percutaneous transhepatic cholangiodrainage and/or surgical intervention (LoE 2b GoR B). Strong consensus (100\%)

\section{Technique}

ESC-D can be performed by a variety of routes depending on the indication, obstruction level and anatomical circumstances. Extrahepatic and intrahepatic routes may be used. Extrahepatic access to a dilated common bile duct is possible with the transducer in the duodenum. Intrahepatic access is normally possible from the stomach or in prior gastrectomy from the jejunum. Biliary drainage may be achieved transmurally along the respective biliary access route (anterograde or retrograde) by bridging the bile duct stricture (anterograde) or by using a trans-papillary rendezvous maneuver (retrograde) ( $\bullet$ Table 2 ). Depending on the individual anatomy and location of the stricture, the choice of drainage route is usually limited [278].

Predominantly described is longitudinal echoendoscopy with a $3.8 \mathrm{~mm}$ working channel and a conventional 19G EUS-FNA needle for the initial puncture of the bile duct. A $19 \mathrm{G}$ needle allows passage of a 0.035 " guidewire, whereas a $22 \mathrm{G}$ needle allows a 0.018 " guidewire $[18,19]$. The selection of the approach route is the most important factor for practical guidewire maneuvering and manipulation in the desired direction [272, 279, 280].

Following stylet removal, bile is aspirated and contrast medium is injected to obtain a cholangiogram. Saline needle flushing pre-
Table 2 Access and drainage routes for ESC-D.

\begin{tabular}{|c|c|}
\hline clinical situation & technique \\
\hline \multicolumn{2}{|l|}{ extrahepatic approach } \\
\hline $\begin{array}{l}\text { papilla reached, but not cannula- } \\
\text { ted }\end{array}$ & $\begin{array}{l}\text { transluminal trans-papillary ESC } \\
\text { rendezvous (ESC-RV) }\end{array}$ \\
\hline $\begin{array}{l}\text { papilla inaccessible or distal ob- } \\
\text { struction (CBD/ampulla/duode- } \\
\text { num or BII resection/gastroen- } \\
\text { terostomy) }\end{array}$ & $\begin{array}{l}\text { transluminal ESC choledocho- } \\
\text { gastrostomy (ESC-G) or duode- } \\
\text { nostomy (ESC-D) as antegrade or } \\
\text { retrograde drainage }\end{array}$ \\
\hline \multicolumn{2}{|l|}{ intrahepatic approach } \\
\hline $\begin{array}{l}\text { papilla inaccessible or obstruction } \\
\text { in the distal part of the CBD with } \\
\text { passage of the guidewire through } \\
\text { the stenosis (BII resection, whip- } \\
\text { ple, hepaticojejunostomy) }\end{array}$ & $\begin{array}{l}\text { transluminal transhepatic ESC } \\
\text { hepatico-gastrostomy (ESC-HG) } \\
\text { or jejunostomy (ESC-HJ) as ante- } \\
\text { grade drainage }\end{array}$ \\
\hline $\begin{array}{l}\text { papilla inaccessible or obstruction } \\
\text { in the proximal part of the CBD } \\
\text { without passage of the guidewire } \\
\text { through the stenosis (intrahepatic } \\
\text { obstruction or Roux-en-Y, hepati- } \\
\text { cojejunostomy) }\end{array}$ & $\begin{array}{l}\text { transluminal transhepatic ESC } \\
\text { hepatico-esophagostomy (ESC- } \\
\text { HE), gastrostomy (ESC-HG) or je- } \\
\text { junostomy (ESC-HJ) as retrograde } \\
\text { drainage }\end{array}$ \\
\hline
\end{tabular}

ESC-D: EUS cholangiography and cholangio-drainage; CBD: common bile duct; BII: Billroth II.

cedes the passage of the guidewire under EUS and fluoroscopy guidance.

In the rendezvous technique, the guidewire is manipulated into the duodenum. The needle and the echoendoscope are removed while maintaining the guidewire in place, with subsequent duodenoscope insertion along the guidewire. Either biliary cannulation is possible along the guidewire or the distal end of the guidewire is grasped with forceps or a snare and pulled out through the working channel. Finally, ERCP is performed using standard techniques [18, 19, 270, 272, 273].

If rendezvous is not feasible, antegrade or retrograde transluminal drainage is achieved with the echoendoscope only. Direct access to the biliary tree with a needle knife with a removable inner needle has been described, but is limited by poor visibility and catheter instability. Most authors use a 19G needle for access, followed by insertion of a 0.035 " guidewire and exchange of the needle for either dilatators ( $6-7$ French), a balloon catheter $(4-6 \mathrm{~mm})$, cystotomes (8.5-10 French) or a Will's ring knife (5 French) in order to dilate the tract [278-282]. Finally, a stent is deployed in the fistula between the biliary tree and the intestine for biliary drainage. Both plastic and specially designed selfexpandable metal stents (SEMS) have been used for ESC-D. No comparative studies exist, but the advantages of metal stents are the larger diameter, better visibility, higher flexibility, and a longer patency. If metal stents are used, partially covered stents are recommended to minimize the risk of biliary leakage. Biliary metal stents are not specifically designed for ESC-D, use is off-label and appropriate informed patient consent is necessary. Special stents and dedicated devices for EUS-guided biliary drainage techniques have been developed [281, $283-288]$.

\section{Technical and clinical outcomes}

A case analysis review $(n=1127)$ reports overall mean technical and clinical success rates of $91 \%$ and $88 \%$, respectively, for ESC-D [171]. A 19-center study reported that when ESC-D was attempted in 106 patients, the technical success rate was low (69\%), which was attributed to inexperience and a steep learning curve. The technical success rate was higher for EUS-related (90\%) vs. 
ERCP-related steps (66\%). Intra-ductal guidewire manipulation was the most restraining aspect, accounting for technical failure in 68 cases [289].

First reported in 2004 [262], other studies have described the rendezvous technique as effective in obtaining biliary cannulation [272, 289-291], with a cumulative success rate (9 studies, $\mathrm{n}=267$ ) of $81 \%$, with a higher success rate for the extrahepatic over the intrahepatic route $(87 \%, n=160$ vs. $65 \%, n=62)$ [272]. The procedure and hospitalization time are significantly shorter for the extrahepatic compared to the intrahepatic approach, and the extrahepatic approach is associated with fewer adverse events, despite similar technical and clinical success rates [292]. Comparing the rendezvous technique $(n=13)$ with the direct transluminal approach $(n=20)$, no significant differences in the technical (94\%) and clinical success rates (97.0\%) or in the frequency of adverse events between the groups have been shown (15\% vs. $10 \%$ ) [293].

A comparison of the outcomes of the intrahepatic and the extrahepatic approach $(n=49)$ in distal malignant biliary obstruction and failed ERCP reported an overall success rate (technical success $96 \%$ vs. $91 \%$ and clinical success $91 \%$ vs. $77 \%$, respectively), and an adverse event rate (20\% vs. $12.5 \%$ ) as similar for both methods [294]. An analysis of the long-term success of ESC-D $(n=240)$ reported no statistically significant difference in the overall success rate between the extrahepatic and intrahepatic approaches (84.3\% vs. $90.4 \%$ ), but when only malignant indications for ESC-D were considered, the intrahepatic approach was superior (success rate $94.9 \%$ vs. $83.8 \%$ ) [267]. This varied from the results of another study in which patients $(n=68)$ underwent either transluminal extrahepatic or intrahepatic ESC-D using metal stents for malignant obstructive jaundice. Technical and clinical results did not differ. The intrahepatic approach was hampered by more adverse events compared to the extrahepatic route ( $31 \%$ vs. $9 \%$ ). Multivariate analysis identified the transhepatic route as the only independent factor associated with procedure risk, with the study concluding that the preferred route is extrahepatic for transluminal and rendezvous stent placement, when both intra- and extrahepatic approaches are feasible [284]. Studies have found lower success rates with the intrahepatic compared with the extrahepatic approach due to a failure to pass a guidewire through the intrahepatic system and stricture $[271,278]$. In a separate study $13 \%$ of intrahepatic approaches were converted to the extrahepatic access route [271]. A rarely used approach with a pooled success rate of $77 \%$ (30/39 cases) is the transhepatic access followed by an intraductal anterograde drainage or dilatation of strictures of the bile duct, papilla or biliodigestive anastomoses [278-281], which may then be combined with transluminal intrahepatic drainage procedures [282].

\section{Recommendation 27}

In EUS-guided biliary interventions, the access and drainage routes should be chosen depending on the indication, level of the biliary obstruction, anatomical condition of the upper gastrointestinal tract, and operator's experience (LOE 2b, GoR B). Strong consensus (100\%)

\section{Recommendation 28}

For ESC-D, guidance and documentation by EUS and fluoroscopy should be available (LoE5, GoR D). Strong consensus (100\%)

\section{Recommendation 29}

The choice of stent (plastic vs. metal) is dependent on the experience of the operator and the access route. If metal stents are used, only partially covered stents are recommended to prevent biliary leakage (LOE 3b, GoR B). Strong consensus (100\%)

\section{Adverse events}

An adverse event rate of $29 \%$ (range $3-77 \%$ ) and a mortality rate of $3 \%$ are reported for ESC-D [171]. A systematic review of 20 papers [43] reported higher adverse events rates for the intrahepatic access route (18\%; pneumoperitoneum $5 \%$, bile leakage $4 \%$, bleeding $4 \%$, stent dysfunction $2 \%$, infection $2 \%$, liver hematoma $1 \%)$, compared to the extrahepatic access route (14\%; pneumoperitoneum $4 \%$, bile leakage $5 \%$, infections $2 \%$, acute pancreatitis and bleeding $1 \%$ ). With the drainage technique, the rendezvous technique resulted in an adverse event rate of $11 \%$ (acute pancreatitis $3.4 \%$, bile leakage $2.7 \%$, pneumoperitoneum $2 \%$, infections $1 \%$, bleeding $0.9 \%$ ), while the transluminal drainage adverse event rate was $21 \%$ (bile leakage $7 \%$, pneumoperitoneum $6 \%$, cholangitis $3.4 \%$, bleeding $2-5 \%$, liver hematoma $2 \%$, infection $2 \%$, miscellaneous $2-3 \%$, and other $2-3 \%$ ) [43]. Comparable results were obtained in a separate review [273].

Lower adverse events are reported by experienced centers [265, $279,280,295]$. In one study complications occurred in 15/95 ESCD (15.7\%), with a single intraperitoneal stent migration in advanced tumor disease responsible for a $1.1 \%$ mortality rate [265]. Another study $(n=101)$ reported an adverse event rate of $11.9 \%$, but the procedure-related mortality rate was as high as $5.9 \%$. However, 5 of the 6 procedure-related fatalities occurred in the first 50 patients [295]. The reported adverse event rates in large multicenter studies are higher [267, 284, 296]. The Spanish National Survey reported an adverse event rate of $23 \%$ for ESC-D, with an overall mortality rate of $4 \%$. Techniques were not standardized, and low patient numbers per center may have contributed with male gender and technical failure as independent predictors of morbidity [289].

Comparative analysis of two prospective studies suggests that the rate of adverse events may be reduced by a defined algorithm of guidewire manipulation, aiming at replacing EUS-guided retrograde transluminal drainage by rendezvous techniques or anterograde internal approach [264, 280].

An evaluation of risk factors for adverse events reported no significant differences between plastic and metal stents [264]. A multicenter trial showed a significant advantage of covered metal stents over plastic stents in terms of reduced frequency of biliary leakage ( $4 \%$ vs. $11 \%$ ) [296].

In a multicenter study $(\mathrm{n}=208)$, the outcomes for self-expandable metal stent placement for malignant distal biliary obstruction using ERCP $(n=104)$ and ESC-D $(n=104)$ were equally successful (94.23\% vs. 93.26\%). There was no difference in the frequency of adverse events between ERCP- and EUS-guided drainage procedures, but the pancreatitis rate was higher in the ERCP group ( $4.8 \%$ vs. $0 \%$ ) [277].

Migration is the main risk with fully covered metal stents. In one study ( $\mathrm{n}=13), 1$ immediate and 3 late migrations occurred [297]. Late migrations were reported in 4/15 patients with normal anatomy [298], and another report found stent dislocations in 9/95 cases with ESC-D. One death was recorded. A patient with advanced carcinoma and malignant ascites experienced a late migration of a transgastric stent into the peritoneal cavity [265]. As 
such, some authors suggest application of either double pigtail plastic stents as anchors or clips for the fixation of the stent $[265,268,272,299]$. No stent migration in a preliminary experience $(n=27)$ with a hybrid metal stent specifically designed for intrahepatic transluminal ESC-D was reported [286].

\section{Recommendation 30}

ESC-D is a technically demanding procedure with a relatively high procedural risk which should be performed only by experienced interventional endosonographers after careful consideration of alternative therapeutic modalities (LoE 2a, GoR B). Strong consensus (100\%)

\section{Recommendation 31}

If EUS-guided treatment fails, immediate drainage must be accomplished with an alternative technique (LoE 5, GoR C). Strong consensus (100\%)

\section{EUS-guided gallbladder drainage}

Transduodenal or transgastric access and drainage routes are feasible for EUS-guided gallbladder drainage using plastic or metal stents, including specifically designed lumen-apposing metal stents [300].

EUS-guided transgastric and transduodenal gallbladder drainage was first reported in 4 patients with advanced pancreaticobiliary malignancies and acute cholecystitis after biliary stenting [301, 302]. This was followed by further reports of EUS-guided gallbladder drainage as an alternative to non-surgical percutaneous or trans-papillary access techniques in patients with acute cholecystitis, who were poor candidates for surgery [303-309]. Pooled data reported a $98 \%$ technical and a $99 \%$ clinical success rate, with adverse events occurring in $<8 \%$ [300].

Similar technical and clinical success rates, but lower pain scores, were reported for EUS-guided gallbladder drainage in prospective comparison to percutaneous gallbladder drainage [310].

\section{Recommendation 32}

In patients with acute cholecystitis unsuitable for cholecystectomy, EUS-guided gallbladder drainage may be considered equivalent to percutaneous transhepatic gallbladder drainage (LOE 1b, GoR B). Strong consensus (100\%)

\section{EUS-guided pancreatography/drainage \\ Background}

Endoscopic therapy is recommended in symptomatic patients with benign pancreatic obstruction due to chronic pancreatitis or post-surgical stenosis [240, 311, 312]. Retrograde pancreatic stenting is technically successful in $85-98 \%$ of cases, with immediate clinical respite seen in $65-95 \%$ but lower pain relief on follow-up only in $32-68 \%$. Stenting can be used as a bridging procedure prior to surgical intervention, as surgery is superior to endoscopic treatment $[122,311,312]$. When ERP fails or surgical intervention is not feasible, alternative techniques are required. EUS-guided pancreatography was first described in a patient with a symptomatic pancreatic duct stone after pancreaticoduodenectomy [313], followed by a few further reports describing
EUS-guided access and interventions of the main pancreatic duct $[171,314]$.

Technique, outcomes and adverse events

In the rendezvous procedure, EUS is only used to obtain transmural access to the main pancreatic duct and to pass the guidewire through the minor or major papilla.

With the anterograde technique, puncture of the main pancreatic duct and stent placement are performed using needles and guidewires through the echoendoscope.

The reported clinical success rate is approximately $75 \%$ (range $53-100 \%$ ) [171], with the adverse event rate reported at $19 \%$ (abdominal pain, pancreatitis, bleeding, perforation, peripancreatic abscess and fluid collections) [314], reflecting the technical challenges of this technique in which re-interventions are often necessary [315].

\section{Recommendation 33}

EUS-guided pancreatography/drainage may be considered after failed ERCP in symptomatic patients with benign pancreatic duct obstruction, inaccessible papilla or disconnected pancreatic tail syndrome (LOE 4, GoR C). Strong consensus $(100 \%)$

\section{Recommendation 34}

EUS-guided pancreatography/drainage should be performed only in referral centers by experienced interventional endosonographers, after multidisciplinary evaluation of alternative therapeutic strategies (LOE 5, GoR C). Strong consensus $(100 \%)$

\section{EUS-guided tumor ablation therapy}

$\nabla$

\section{Background}

EUS-guided tumor ablation includes ethanol and antitumor agent delivery, radiofrequency ablation (RFA), photodynamic treatment, implantation of radioactive seeds for brachytherapy and gold or silver fiducials to 'target' image-guided targeted radiation therapy. These therapies have been used for pancreatic cancer, pancreatic cystic lesions, pancreatic neuroendocrine tumors, and other malignant tumors.

\section{EUS-guided ethanol ablation}

Cystic pancreatic lesions

Pancreatic cystic tumors, either mucinous or non-mucinous, are often detected incidentally in asymptomatic patients undergoing imaging procedures [316]. Surgical resection is usually the treatment of choice for mucinous cystic tumors. However, EUS-guided ethanol lavage has been suggested as an alternative when patients are not fit for surgery [317]. The cyst is usually punctured with a $22 \mathrm{G}$ or $19 \mathrm{G}$ fine needle under EUS guidance, the fluid is aspirated, and ethanol is injected into the cyst and re-aspirated after 3-5 min [317]. The feasibility and safety of EUS-guided ethanol lavage for pancreatic cystic tumors was described in 25 patients, with complete cyst ablation observed in 35 [318]. A comparison $(n=42)$ of the change of pancreatic cyst size after EUS-guided lavage with either $80 \%$ ethanol or saline solution demonstrated complete cyst ablation in $33 \%$ of cases after 1 or 2 
ethanol injections vs. $11 \%$ after 1 or 2 saline injections. However, histology of resected cysts $(n=4)$ showed complete ablation of neoplastic epithelium in only 1 patient [319]. Follow-up showed no cyst recurrence [320].

Repeated EUS-guided ethanol lavage for suspected branch-duct IPMN without morphological criteria for malignancy achieved cyst resolution in 5/13 patients after failure of the initial EUSguided ethanol lavage [321].

EUS-guided ethanol lavage was applied in small mucinous cystic tumors of the pancreas $(n=13)$ not suitable for surgery with a response rate of $85 \%$ [322]. Other studies have combined ethanol lavage with injection of paclitaxel, a viscous, hydrophobic chemotherapeutic agent believed to have a prolonged effect [323]. A description of 14 patients with pancreatic cystic lesions treated with ethanol lavage and paclitaxel injection [323] confirmed the technical feasibility and good results of a larger series $(n=52)$ [324]. In the larger study, complete response was achieved in $29 / 52$ patients (62\%), with small cyst volume being predictive for treatment response [324]. The technique is also reported to be feasible in septated cystic lesions [325]. In a study of 22 patients with suspected benign pancreatic cysts, treatment with EUS-guided pancreatic cyst ablation with ethanol and paclitaxel was performed, followed at 3 months by repeat EUS-FNA for DNA analysis and possible repeat treatment. Complete and partial response was observed in $50 \%$ of patients ( $3-4$ months) and $25 \%$ of patients (12 months after the second EUS-guided intervention) [326]. Post-ablation fluid analysis showed elimination of all baseline mutations in 8/19 patients, new mutations in 3 patients, and unchanged mutational status in 8 patients [326]. The plasma paclitaxel concentration after EUS-guided pancreatic cyst ablation was shown to be nearly undetectable and rarely caused systemic side-effects [327]. A meta-analysis of 7 studies $(n=152)$ reported complete cyst resolution in $56.2 \%$ of cases and partial cyst resolution in $23.7 \%$ of patients following EUSguided ethano ablation [328]. Overall, the frequency of adverse events reported in these studies including hyperamylasemia, abdominal pain, acute pancreatitis, fever, and rarely portal and splenic vein thrombosis [329] was in a range between $0 \%$ [321] and $29 \%$ [327]. Abdominal pain (mean, $6.5 \%$ ) and pancreatitis (mean, 3.9\%) were the most frequent complications [328].

\section{Pancreatic neuroendocrine tumors}

Pancreatic neuroendocrine tumors account for $1 \%$ of all pancreatic tumors, but their incidence is increasing. Although surgical enucleation or resection is the treatment of choice, EUS-guided ablation therapy using $95-98 \%$ ethanol is described in patients unfit for surgery [330 - 335]. Experimental studies in pigs have shown that EUS-guided injection of $2 \mathrm{ml}$ of $40 \%-100 \%$ ethanol results in localized concentration-dependent pancreatic parenchymal necrosis of approximately $20 \mathrm{~mm}$ without adverse events [336, 337]. EUS-guided ethanol ablation of symptomatic sporadic insulinoma (size range 5-21 mm) was reported in 13 patients not fit for surgery. The step-wise injected volume was calibrated by extension of a hyperechoic blush within the tumor, ranging from $0.3 \mathrm{ml}$ to $8 \mathrm{ml}$. Resolution of symptoms with euglycemia was achieved in all patients, with a single episode of mild procedure-associated pancreatitis and one hematoma with ulceration of the duodenal wall recorded, both with relatively high injected volumes (3.5 $\mathrm{ml}$ and $8 \mathrm{ml}$, respectively) [330 - 335]. Two neuroendocrine tumors were treated by EUS-guided injection of $40 \%$ ethanol in a patient with MEN 1 with subsequent normalization of the levels of vasoactive intestinal peptide and chromogranin A. The main adverse event was a small pancreatic necrosis, presumably caused by minimal ethanol effusion in a second injection session and managed by laparoscopic necrosectomy [338].

Successful EUS-guided ethanol injection treatment has been described also in solitary metastatic lymph nodes [339, 340], gastrointestinal stromal tumor [341], solitary hepatic metastases $[342,343]$ and left adrenal metastasis [344].

\section{EUS-guided injection of anti-tumoral agents}

Pilot and phase 1 - 2 studies report direct EUS-guided injection of several anti-tumoral agents into unresectable pancreatic tumors. These include cytoimplant, an allogeneic mixed lymphocyte culture [345], dendritic cells [346 - 348], TNFerade, a replication deficient adenovirus that expresses the tumor necrosis factor alpha [349-351], and Onyx-015, a selective adenovirus that preferentially replicates inside malignant cells [352]. Due to a substantial lack of efficacy despite the minimal number of adverse events encountered, these techniques have not become established in clinical practice.

\section{Cytoimplant}

A phase I trial reported on EUS-guided fine needle injection (FNI) of an allogeneic mixed lymphocyte culture (cytoimplant) in 8 patients with unresectable pancreatic cancer. The cytoimplant was generated from a co-culture of healthy donor and patient peripheral blood mononuclear cells to stimulate the release of cytokines and activation of immune effector cells. Escalating doses of cells were implanted into the pancreatic tumor by a single EUS-FNI. Two patients experienced partial response [345].

\section{Dendritic cells}

EUS-FNI in human pancreatic cancer of dendritic cells alone or in combination with gemcitabine was used in small series of patients for unresectable pancreatic cancer with promising albeit still preliminary results [346-348].

\section{TNFerade}

Injection of specific gene products with the purpose of selective replication in tumor cells has been reported in prospective studies for pancreatic cancer and esophageal cancer. TNFerade is a replication deficient adenovirus that expresses the tumor necrosis factor alpha (TNF $\alpha$ ) controlled by EGR-1, a promoter inducible by radiation or chemotherapy. A phase I evaluation of EUS-guided intratumoral injection of TNFerade combined with chemoradiation before esophagectomy in 24 patients with locally advanced resectable esophageal cancer reported a complete response in six patient, and this multimodal treatment was associated with long-term survival. However, comparative studies are warranted [349]. Promising results with a phase I/II study of weekly EUSguided or percutaneous injection of TNFerade (repeated for five weeks) combined with chemoradiation was reported in 50 patients with advanced pancreatic cancer [350]. The patients received $50.4 \mathrm{GY}$ radiation and $5 F U 200 \mathrm{mg} / \mathrm{m}^{2} \mathrm{x} 2$ for 5.5 weeks. 4 patients had complete or partial response, 7 patients could undergo surgery after the treatment, 6 of these had free resection margins, and 3 survived more than 3 months. Severe toxicity occurred in 3 patients. However, a subsequent RCT evaluating this protocol failed to show any advantage of the combined treatment vs. chemoradiation alone in terms of survival [351]. Gemcitabine offers modest improvement over 5-fluorouracil in patients with unresectable pancreatic cancer and in the adjuvant setting after 
curative resection. Preliminary results of EUS-guided injection of gemcitabine were reported in 36 patients with unresectable pancreatic cancer [353].

\section{ONYX-015}

ONYX-015 is a selective adenovirus that preferentially replicates in malignant cells, leading to cell death. A phase I/II trial of EUSguided injection of ONYX-015 in 21 patients with pancreatic cancer failed to show tumor regression before initiation of gemcitabine, at the cost of severe adverse events in 4 patients [352].

\section{EUS-guided radiofrequency ablation}

RFA is used to ablate neoplastic tissue by local thermal-induced coagulative necrosis of the tumor [354]. Ablation in the pancreas is hazardous without real-time imaging and without additional cooling of adjacent tissue whilst treating the pancreatic head. For percutaneous RFA of unresectable pancreatic cancer, a systematic review of 5 pilot series $(n=158)$ reported feasibility, a median survival after RFA of 3-33 months, and a procedurerelated morbidity and mortality of $4-37 \%$ and $0-19 \%$, respectively $[355,356]$. The results and safety of EUS-guided RFA (liver, pancreas, lymph nodes) have been evaluated only in animal experiments with encouraging results [357-361], and only in a few human patients with pancreatic tumors [362, 363]. The combination of cryotherapy and RFA has the advantage of the two technologies: the more effective cooling by cryogenic gas permits more RF-induced interstitial devitalizing effects than heat alone. Less power is needed than with conventional RFA systems to obtain the same result, resulting in less collateral damage. Under EUS guidance, the cryothermal probe, a flexible bipolar device that combines radiofrequency with cryogenic cooling, was used to treat 22 patients with unresectable stage III pancreatic adenocarcinoma with fixed RF power (heating) of $18 \mathrm{~W}$ and fixed pressure (cooling). Technical problems prohibited application of the probe in $27 \%$ of patients. The effect of this treatment was difficult to determine. Although severe procedure-related adverse events were not observed, only 6 patients seemed to benefit from partial tumor regression [363]. Experimental studies have been performed for EUS-guided photodynamic therapy and Nd:YAG-laser treatment [364-367].

\section{EUS-guided interstitial brachytherapy}

EUS guidance can also be used to implant intra-tumoral radioactive seeds. This is a safe, simple and minimally invasive technique for interstitial brachytherapy of the pancreas. However, the biological effectiveness of $\mathrm{I}^{125}$ seeds in pancreatic cancer cells has yet to be determined.

EUS-guided $\mathrm{I}^{125}$ implantation was technically feasible in 15 patients with unresectable pancreatic cancer, 8 with stage III disease and 7 with stage IV disease [368]. The clinical efficacy and safety of EUS-guided implantation of radioactive ${ }^{125}$ seeds in advanced pancreatic cancer was evaluated with routine gemcitabine-based 5-FU chemotherapy 1 week after brachytherapy [23]. Compared with brachytherapy alone [369], the combination of chemotherapy and radioactive $\mathrm{I}^{125}$ seeds did not demonstrate better tumor response nor long-term effects. Partial tumor response and pain relief were observed in $27 \%$ and $30 \%$ of patients, respectively. Local adverse events or grade III toxicity developed in $40 \%$ of patients [369]. Radioactive metal seeds have also been applied in metastatic lymph nodes in the retroperitoneum and in the mediastinum, but with only single reported cases describing response to treatment [370].
EUS-guided intratumoral placement of fiducial markers Stereotactic body radiation therapy relies on image-guided radiotherapy to allow radiation dose escalation to tumors with simultaneous sparing of surrounding normal tissue through the use of imaging to verify target delineation and treatment delivery. Fiducial markers are useful to facilitate the quantification of respiratory-associated tumor motion [371] and allow reproducible daily treatment delivery. Fiducial markers include radiopaque spheres, coils, or seeds that are implanted in or near the tumor. EUS-guided fiducial placement has been reported to be feasible and safe in several studies of inoperable pancreatic, abdominal or mediastinal malignancy [171, 372 -376]. The reported success rate is between $84.6 \%$ and $100 \%$, and adverse events are few (7/ $278,2.5 \%$ ) and limited to mild pancreatitis, abdominal pain and infection [171]. In inoperable pancreatic cancer or hepatic malignant lesions eligible for radiation therapy $(n=32)$, a $100 \%$ success rate in placing $2-3$ fiducials per patient was reported. One case of mild pancreatitis and one fiducial migration were observed [377]. High success rates were also reported for EUS-guided placement of gold fiducials in malignant gastrointestinal lesions $[372,373]$ and for primary and recurrent prostate cancer [374, 375]. Similar results from experienced centers were reported $[378,379]$, with adverse event rates at $2 \%$ and migration rates $7 \%$ and with $91 \%$ of the patients able to undergo stereotactic radiation therapy guided by the EUS-placed fiducials [379]. EUSguided placement of fiducials has also been described to guide parenchymal-sparing pancreatic surgery of small pancreatic neuroendocrine tumors [380].

Two major problems of the EUS-guided placement of fiducials are migration before beginning the targeted image-guided radiation treatment and deviation from ideal fiducial geometry. Comparison of surgical and EUS-guided fiducial implantation in locally advanced pancreatic cancer was performed. The ideal fiducial geometry was more often achieved with surgical placement compared with the EUS-guided approach ( $47 \%$ vs. $18 \%$ ). Nevertheless, the success rate of fiducial tracking for Cyberknife therapy was equally high in both groups ( $82 \%$ vs. $90 \%$ ) [381]. A comparative analysis of traditional fiducials ( $5 \mathrm{~mm}$ length and $0.8 \mathrm{~mm}$ diameter) and Visicoil fiducials (Core oncology, Santa Barbara, CA; $10 \mathrm{~mm}$ length and $0.35 \mathrm{~mm}$ diameter) implanted under EUS guidance demonstrated that the mean migration was not significantly different [382]. A report of the insertion of two different designs of fiducials, the Visicoil and the Gold Anchor fiducial (Naslund Medical AB, Huddinge, Sweden), using a $22 \mathrm{G}$ needle and the transduodenal route $(n=23)$ encountered technical difficulties in $11.3 \%$ of cases typically in the unloading of the Gold Anchor fiducials. A total migration rate of $9.5 \%$ was observed, predominantly of Visicoil fiducials. $95 \%$ of patients were able to undergo image-guided radiation therapy, and the infection rate was negligible even without prophylactic antibiotics [383].

Depending on the type of fiducial, 22G and 19G needles can be used for application. Currently fiducials have been front-loaded into EUS needles and injected using the stylet or a water jet. However, a new $22 \mathrm{G}$ needle prototype preloaded with four gold fiducials was shown to provide quick, easy and safe fiducial deployment in an animal study [384]. The development of dedicated fiducial needles may help integrate fiducial placement for image-guided radiation therapy in the clinical workflow and as a routine component of EUS. 
Recommendation 35

EUS-guided local ablative procedures for pancreatic cystic neoplasms are not recommended outside experimental protocols (LoE 2b, GoR B). Strong consensus (100\%)

\section{Recommendation 36}

Ablation of symptomatic insulinoma by EUS-guided ethanol injection should be considered in patients not suitable for surgery in whom medical treatment is insufficient to control symptoms (LoE 4, GoR C). Strong consensus (100\%)

\section{Recommendation 37}

EUS-guided placement of fiducials for image-guided radiation therapy is safe and technically feasible in locally advanced cancer, as an alternative to surgical or image-guided percutaneous placement (LoE 2b, GoR B). Strong consensus (100\%)

\section{Affiliations}

Gastroenterology Unit, Department of Medical and Surgical Sciences University of Bologna/Hospital of Imola, Italy

2 Department of Internal Medicine, Krankenhaus Märkisch Oderland, Strausberg/ Wriezen, Germany

3 Department of Internal Medicine 2, Helios Hospital Meiningen GmbH, Meiningen, Germany

4 Department of Internal Medicine I, Sana Kliniken, Luebeck, Germany

UO Gastroenterologia, Ospedale Maggiore Crema, Italy

6 Department of Medicine and National Centre for Ultrasound in Gastroenterology, Haukeland University Hospital, Bergen, Norway

7 Department of Internal Medicine 2, Caritas Krankenhaus, Bad Mergentheim Germany

8 Department of Gastroenterology, Research Center of Gastroenterology and Hepatology, University of Medicine and Pharmacy, Craiova, Romania and Department of Endoscopy, Gastrointestinal Unit, Copenhagen University Hospital Herlev, Denmark

${ }^{9}$ Gastrointestinal Unit, Department of Surgery, University Hospital Herlev, Copenhagen, Denmark

10 Department of Gastric Surgery, Ultrasound Section, Herlev Hospital, University of Copenhagen, Denmark

11 Department of Gastroenterology, Brandenburg University of Medicine Theodor Fontane, Neuruppin, Germany

12 Department of Radiology, GB Rossi University Hospital, University of Verona, Italy

13 National Centre for Ultrasound in Gastroenterology, Haukeland University Hospital, Bergen and Department of Clinical Medicine, University of Bergen, Bergen, Norway

14 Unit of Internal Medicine, Dept of Medical and Surgical Sciences, University of Bologna/Hospital S.Orsola Malpighi, Bologna, Italy

15 Department of Radiology, King's College Hospital, London, UK

16 Sino-German Research Center of Ultrasound in Medicine, The First Affiliated Hospital of Zhengzhou University, Zhengzhou, China

\section{References}

1 Jenssen $C$, Hocke $M$, Fusaroli $P$ et al. EFSUMB guidelines on interventional ultrasound, part IV. EUS-guided interventions: General aspects and EUS-guided sampling. Ultraschall in Med 2015, Epub ahead of print

2 Dietrich CF, Lorentzen T, Sidhu PS et al. An introduction into the EFSUMB guidelines on interventional ultrasound. Ultraschall in Med 2015; 36: 460-463

3 Penman ID, Rosch T. Group EUSW. EUS 2008 Working Group document: evaluation of EUS-guided celiac plexus neurolysis/block (with video). Gastrointest Endosc 2009; 69: S28 - S31

4 Arcidiacono PG, Calori $G$, Carrara $S$ et al. Celiac plexus block for pancreatic cancer pain in adults. Cochrane Database Syst Rev 2011, CD007519
5 Nagels $W$, Pease $N$, Bekkering $G$ et al. Celiac plexus neurolysis for abdominal cancer pain: a systematic review. Pain Med 2013; 14: 1140 1163

6 Yan BM, Myers RP. Neurolytic celiac plexus block for pain control in unresectable pancreatic cancer. Am J Gastroenterol 2007; 102: 430 - 438

7 Zhong $W$, Yu Z, Zeng JX et al. Celiac plexus block for treatment of pain associated with pancreatic cancer: a meta-analysis. Pain Pract 2014; 14: $43-51$

8 Wiersema MJ, Wiersema LM. Endosonography-guided celiac plexus neurolysis. Gastrointest Endosc 1996; 44: 656-662

9 Gerke H, Silva RG Jr, Shamoun D et al. EUS characteristics of celiac ganglia with cytologic and histologic confirmation. Gastrointest Endosc 2006; 64: 35-39

10 Levy M, Rajan E, Keeney G et al. Neural ganglia visualized by endoscopic ultrasound. Am J Gastroenterol 2006; 101: 1787-1791

11 Gleeson FC, Levy MJ, Papachristou GI et al. Frequency of visualization of presumed celiac ganglia by endoscopic ultrasound. Endoscopy 2007; 39: $620-624$

$12 \mathrm{Ha} \mathrm{TI}$, Kim GH, Kang DH et al. Detection of celiac ganglia with radial scanning endoscopic ultrasonography. Korean J Intern Med 2008; 23: $5-8$

13 Levy MJ, Topazian MD, Wiersema MJ et al. Initial evaluation of the efficacy and safety of endoscopic ultrasound-guided direct Ganglia neurolysis and block. Am J Gastroenterol 2008; 103: 98-103

14 Fusaroli P, Ceroni L, Caletti G. Forward-view Endoscopic Ultrasound: A Systematic Review of Diagnostic and Therapeutic Applications. Endosc Ultrasound 2013; 2: $64-70$

15 Gress F, Schmitt C, Sherman $S$ et al. Endoscopic ultrasound-guided celiac plexus block for managing abdominal pain associated with chronic pancreatitis: a prospective single center experience. Am J Gastroenterol 2001; 96: 409-416

16 Collins D, Penman I, Mishra G et al. EUS-guided celiac block and neurolysis. Endoscopy 2006; 38: 935 - 939

17 Penman ID, Gilbert D. Basic technique for celiac plexus block/neurolysis. Gastrointest Endosc 2009; 69: S163 - S165

18 Dietrich CF, Hocke $M$, Jenssen $C$. Interventional endosonography. Ultraschall in Med 2011; 32: 8-22 quiz 23-25

19 Dietrich $C F$, Hocke $M$, Jenssen $C$. Interventional endosonography. In: Dietrich CF, Nuernberg D eds. Interventional Ultrasound. A Practical Guide and Atlas. Stuttgart, New York, Delhi, Rio: Thieme; 2015: 224 253

20 Adler DG, Conway JD, Coffie JM et al. EUS accessories. Gastrointest Endosc 2007; 66: 1076-1081

21 Ishiwatari H, Hayashi T, Yoshida M et al. Phenol-based endoscopic ultrasound-guided celiac plexus neurolysis for East Asian alcohol-intolerant upper gastrointestinal cancer patients: a pilot study. World J Gastroenterol 2014; 20: 10512 - 10517

22 Wang KX, Jin ZD, Du YQ et al. EUS-guided celiac ganglion irradiation with iodine-125 seeds for pain control in pancreatic carcinoma: a prospective pilot study. Gastrointest Endosc 2012; 76: 945 -952

23 Jin Z, Du Y, Li Z et al. Endoscopic ultrasonography-guided interstitial implantation of iodine 125-seeds combined with chemotherapy in the treatment of unresectable pancreatic carcinoma: a prospective pilot study. Endoscopy 2008; 40: $314-320$

24 Puli SR, Reddy JB, Bechtold ML et al. EUS-guided celiac plexus neurolysis for pain due to chronic pancreatitis or pancreatic cancer pain: a metaanalysis and systematic review. Dig Dis Sci 2009; 54: 2330-2337

25 Kaufman M, Singh G, Das S et al. Efficacy of endoscopic ultrasoundguided celiac plexus block and celiac plexus neurolysis for managing abdominal pain associated with chronic pancreatitis and pancreatic cancer. J Clin Gastroenterol 2010; 44: 127-134

26 Wyse JM, Carone M, Paquin SC et al. Randomized, double-blind, controlled trial of early endoscopic ultrasound-guided celiac plexus neurolysis to prevent pain progression in patients with newly diagnosed, painful, inoperable pancreatic cancer. J Clin Oncol 2011; 29: 3541 3546

27 Sahai AV, Lemelin V, Lam E et al. Central vs. bilateral endoscopic ultrasound-guided celiac plexus block or neurolysis: a comparative study of short-term effectiveness. Am J Gastroenterol 2009; 104: 326-329

28 LeBlanc JK, Al-Haddad M, McHenry L et al. A prospective, randomized study of EUS-guided celiac plexus neurolysis for pancreatic cancer: one injection or two? Gastrointest Endosc 2011; 74: 1300-1307

29 Tellez-Avila FI, Romano-Munive AF, de Jesús Herrera-Esquivel J et al. Central is as effective as bilateral endoscopic ultrasound-guided celiac 
plexus neurolysis in patients with unresectable pancreatic cancer. Endosc Ultrasound 2013; 2: 153-156

30 Ascunce G, Ribeiro A, Reis I et al. EUS visualization and direct celiac ganglia neurolysis predicts better pain relief in patients with pancreatic malignancy (with video). Gastrointest Endosc 2011; 73: 267-274

31 Doi S, Yasuda I, Kawakami H et al. Endoscopic ultrasound-guided celiac ganglia neurolysis vs. celiac plexus neurolysis: a randomized multicenter trial. Endoscopy 2013; 45: 362-369

32 Iwata K, Yasuda I, Enya $M$ et al. Predictive factors for pain relief after endoscopic ultrasound-guided celiac plexus neurolysis. Dig Endosc 2011; 23: $140-145$

33 Sakamoto H, Kitano M, Kamata K et al. EUS-guided broad plexus neurolysis over the superior mesenteric artery using a 25-gauge needle. Am J Gastroenterol 2010; 105: 2599-2606

34 Leblanc JK, Rawl S, Juan M et al. Endoscopic Ultrasound-Guided Celiac Plexus Neurolysis in Pancreatic Cancer: A Prospective Pilot Study of Safety Using $10 \mathrm{~mL}$ versus $20 \mathrm{~mL}$ Alcohol. Diagn Ther Endosc 2013; 2013: 327036

35 Si-Jie H, Wei-Jia X, Yang D et al. How to improve the efficacy of endoscopic ultrasound-guided celiac plexus neurolysis in pain management in patients with pancreatic cancer: analysis in a single center. Surg Laparosc Endosc Percutan Tech 2014; 24: 31 - 35

36 Sey MS, Schmaltz L, Al-Haddad MA et al. Effectiveness and safety of serial endoscopic ultrasound-guided celiac plexus block for chronic pancreatitis. Endosc Int Open 2015; 3: E56-E59

37 Stevens $T$, Costanzo A, Lopez $R$ et al. Adding triamcinolone to endoscopic ultrasound-guided celiac plexus blockade does not reduce pain in patients with chronic pancreatitis. Clin Gastroenterol Hepatol 2012; 10: $186-191,191$ e181

38 Eisendrath P, Paquin SC, Delhaye M et al. A Randomized, double-blinded, multi-center, sham-controlled trial of EUS-guided celiac plexus block for pain due to chronic pancreatitis (abstract). Gastrointest Endosc 2014; 79: AB168

39 LeBlanc JK, DeWitt J, Johnson C et al. A prospective randomized trial of 1 versus 2 injections during EUS-guided celiac plexus block for chronic pancreatitis pain. Gastrointest Endosc 2009; 69: 835-842

40 Gress F, Schmitt C, Sherman $S$ et al. A prospective randomized comparison of endoscopic ultrasound- and computed tomography-guided celiac plexus block for managing chronic pancreatitis pain. Am J Gastroenterol 1999; 94: 900-905

41 Santosh D, Lakhtakia S, Gupta R et al. Clinical trial: a randomized trial comparing fluoroscopy guided percutaneous technique vs. endoscopic ultrasound guided technique of coeliac plexus block for treatment of pain in chronic pancreatitis. Aliment Pharmacol Ther 2009; 29: 979984

42 O'Toole TM, Schmulewitz N. Complication rates of EUS-guided celiac plexus blockade and neurolysis: results of a large case series. Endoscopy 2009; 41: 593-597

43 Alvarez-Sanchez MV, Jenssen C, Faiss S et al. Interventional endoscopic ultrasonography: an overview of safety and complications. Surg Endosc 2014; 28: 712-734

44 McGreevy K, Hurley RW, Erdek MA et al. The effectiveness of repeat celiac plexus neurolysis for pancreatic cancer: a pilot study. Pain Pract 2013; 13: 89-95

45 Luz LP, Al-Haddad MA, DeWitt JA. EUS-guided celiac plexus interventions in pancreatic cancer pain: An update and controversies for the endosonographer. Endosc Ultrasound 2014; 3: 213-220

46 El-Saadany $M$, Jalil S, Irisawa A et al. EUS for portal hypertension: a comprehensive and critical appraisal of clinical and experimental indications. Endoscopy 2008; 40: 690-696

47 Faigel DO, Rosen HR, Sasaki A et al. EUS in cirrhotic patients with and without prior variceal hemorrhage in comparison with noncirrhotic control subjects. Gastrointest Endosc 2000; 52: 455-462

48 Burtin $P$, Cales $P$, Oberti $F$ et al. Endoscopic ultrasonographic signs of portal hypertension in cirrhosis. Gastrointest Endosc 1996; 44: 257 261

49 Lee YT, Chan FK, Ching JY et al. Diagnosis of gastroesophageal varices and portal collateral venous abnormalities by endosonography in cirrhotic patients. Endoscopy 2002; 34: 391 - 398

50 Sharma M, Babu CSR, Garg S et al. Portal Venous System and Its Tributaries: A Radial Endosonographic Assessment. Endoscopic Ultrasound 2012; 1: $96-107$

51 Leung VK, Sung JJ, Ahuja AT et al. Large paraesophageal varices on endosonography predict recurrence of esophageal varices and rebleeding. Gastroenterology 1997; 112: 1811-1816
52 Kume K, Yamasaki M, Watanabe T et al. Mild collateral varices and a fundic plexus without perforating veins on EUS predict endoscopic non-recurrence of esophageal varices after EVL. Hepatogastroenterology 2011; 58: 798-801

53 Liao SC, Yang SS, Ko CW et al. A miniature ultrasound probe is useful in reducing rebleeding after endoscopic cyanoacrylate injection for hemorrhagic gastric varices. Scand J Gastroenterol 2013; 48: 1347 - 1353

54 Cattan P, Cuillerier E, Cellier $C$ et al. Hemobilia caused by a pseudoaneurysm of the hepatic artery diagnosed by EUS. Gastrointest EndosC 1999; 49: $252-255$

55 Falodia S, Garg PK, Bhatia $V$ et al. EUS diagnosis of a left gastric artery pseudoaneurysm and aneurysmogastric fistula seen with a massive Gl hemorrhage (with video). Gastrointest Endosc 2008; 68: 389-391

56 Fukatsu K, Ueda K, Maeda $\mathrm{H}$ et al. A case of chronic pancreatitis in which endoscopic ultrasonography was effective in the diagnosis of a pseudoaneurysm. World J Gastrointest Endosc 2012; 4: 335-338

57 Varshney P, Songra B, Mathur $S$ et al. Splenic artery pseudoaneurysm presenting as massive hematemesis: a diagnostic dilemma. Case Rep Surg 2014; 2014: 501937

58 Pinto-Marques P, Giria J, Brito $M$ et al. Unusual cause for upper GI bleeding: a splenic artery aneurysm mimicking a Dieulafoy lesion. Role for systematic EUS assessment? Gastrointest Endosc 2010; 71: 845 - 846 discussion 847

59 Fockens P, Meenan J, van Dullemen HM et al. Dieulafoy's disease: endosonographic detection and endosonography-guided treatment. Gastrointest Endosc 1996; 44: 437-442

60 Levy MJ, Wong Kee Song LM, Farnell MB et al. Endoscopic ultrasound (EUS)-guided angiotherapy of refractory gastrointestinal bleeding. Am J Gastroenterol 2008; 103: 352 - 359

61 Gubler C, Bauerfeind P. Safe and successful endoscopic initial treatment and long-term eradication of gastric varices by endoscopic ultrasoundguided Histoacryl (N-butyl-2-cyanoacrylate) injection. Scand J Gastroenterol 2014; 49: 1136-1142

62 de Paulo GA, Ardengh JC, Nakao FS et al. Treatment of esophageal varices: a randomized controlled trial comparing endoscopic sclerotherapy and EUS-guided sclerotherapy of esophageal collateral veins. Gastrointest Endosc 2006; 63: 396-402; quiz 463

63 Lahoti S, Catalano MF, Alcocer E et al. Obliteration of esophageal varices using EUS-guided sclerotherapy with color Doppler. Gastrointest Endosc 2000; 51: 331 - 333

64 Romero-Castro R, Ellrichmann M, Ortiz-Moyano C et al. EUS-guided coil versus cyanoacrylate therapy for the treatment of gastric varices: a multicenter study (with videos). Gastrointest Endosc 2013; 78: 711 721

65 Romero-Castro R, Pellicer-Bautista FJ, Jimenez-Saenz M et al. EUS-guided injection of cyanoacrylate in perforating feeding veins in gastric varices: results in 5 cases. Gastrointest Endosc 2007; 66: 402-407

66 Hwang SS, Kim HH, Park SH et al. N-butyl-2-cyanoacrylate pulmonary embolism after endoscopic injection sclerotherapy for gastric variceal bleeding. J Comput Assist Tomogr 2001; 25: 16-22

67 Binmoeller KF, Weilert F, Shah JN et al. EUS-guided transesophageal treatment of gastric fundal varices with combined coiling and cyanoacrylate glue injection (with videos). Gastrointest Endosc 2011; 74: $1019-1025$

68 Mosli MH, Aljudaibi B, Almadi M et al. The safety and efficacy of gastric fundal variceal obliteration using N-butyl-2-cyanoacrylate; the experience of a single canadian tertiary care centre. Saudi J Gastroenterol 2013; 19: $152-159$

69 Kinzel J, Pichetshote N, Dredar S et al. Bleeding from a duodenal varix: a unique case of variceal hemostasis achieved using EUS-guided placement of an embolization coil and cyanoacrylate. J Clin Gastroenterol 2014; 48: $362-364$

70 Levy MJ, Wong Kee Song LM, Kendrick ML et al. EUS-guided coil embolization for refractory ectopic variceal bleeding (with videos). Gastrointest Endosc 2008; 67: 572-574

71 Connor EK, Duran-Castro OL, Attam R. Therapy for recurrent bleeding from rectal varices by EUS-guided sclerosis. Gastrointest Endosc 2015; 81: 1280-1281

72 Krystallis C, McAvoy NC, Wilson J et al. EUS-assisted thrombin injection for ectopic bleeding varices-a case report and review of the literature. QJM 2012; 105: 355-358

73 Rana SS, Bhasin DK, Rao C et al. Endoscopic ultrasound-guided treatment of bleeding duodenal varix. Indian J Gastroenterol 2011; 30: $280-281$ 
74 Weilert F, Shah JN, Marson FP et al. EUS-guided coil and glue for bleeding rectal varix. Gastrointest Endosc 2012; 76: 915-916

75 Sharma M, Somasundaram A. Massive lower GI bleed from an endoscopically inevident rectal varices: diagnosis and management by EUS (with videos). Gastrointest Endosc 2010; 72: 1106 - 1108

76 Gonzalez JM, Giacino C, Pioche $M$ et al. Endoscopic ultrasound-guided vascular therapy: is it safe and effective? Endoscopy 2012; 44: 539 542

77 Ribeiro A, Vazquez-Sequeiros E, Wiersema MJ. Doppler EUS-guided treatment of gastric Dieulafoy's lesion. Gastrointest Endosc 2001; 53 : 807-809

78 Law R, Fujii-Lau L, Wong Kee Song LM et al. Efficacy of Endoscopic Ultrasound-Guided Hemostatic Interventions for Resistant Nonvariceal Bleeding. Clin Gastroenterol Hepatol 2015; 13: 808-812.e1

79 Lameris R, du Plessis J, Nieuwoudt $M$ et al. A visceral pseudoaneurysm: management by EUS-guided thrombin injection. Gastrointest Endosc 2011; 73: $392-395$

80 Robinson $M$, Richards $D$, Carr $N$. Treatment of a splenic artery pseudoaneurysm by endoscopic ultrasound-guided thrombin injection. Cardiovasc Intervent Radiol 2007; 30: 515-517

81 Chaves DM, Costa FF, Matuguma $S$ et al. Splenic artery pseudoaneurysm treated with thrombin injection guided by endoscopic ultrasound. Endoscopy 2012; 44 (Suppl 2): UCTN:E99-E100

82 Roach $H$, Roberts SA, Salter $R$ et al. Endoscopic ultrasound-guided thrombin injection for the treatment of pancreatic pseudoaneurysm. Endoscopy 2005; 37: 876-878

83 Roberts KJ, Jones RG, Forde C et al. Endoscopic ultrasound-guided treatment of visceral artery pseudoaneurysm. HPB (Oxford) 2012; 14: $489-490$

84 Gonzalez JM, Ezzedine S, Vitton $V$ et al. Endoscopic ultrasound treatment of vascular complications in acute pancreatitis. Endoscopy 2009; 41: $721-724$

85 Magno P, Ko CW, Buscaglia JM et al. EUS-guided angiography: a novel approach to diagnostic and therapeutic interventions in the vascular system. Gastrointest Endosc 2007; 66: 587-591

86 Giday SA, Clarke JO, Buscaglia JM et al. EUS-guided portal vein catheterization: a promising novel approach for portal angiography and portal vein pressure measurements. Gastrointest Endosc 2008; 67: 338 - 342

87 Brugge WR. EUS is an important new tool for accessing the portal vein. Gastrointest Endosc 2008; 67: 343-344

88 Lai L, Poneros J, Santilli J et al. EUS-guided portal vein catheterization and pressure measurement in an animal model: a pilot study of feasibility. Gastrointest Endosc 2004; 59: 280-283

89 Matthes K, Sahani D, Holalkere NS et al. Feasibility of endoscopic ultrasound-guided portal vein embolization with Enteryx. Acta Gastroenterol Belg 2005; 68: $412-415$

90 Buscaglia JM, Dray X, Shin EJ et al. A new alternative for a transjugular intrahepatic portosystemic shunt: EUS-guided creation of an intrahepatic portosystemic shunt (with video). Gastrointest Endosc 2009; 69: $941-947$

91 Banks PA, Bollen TL, Dervenis C et al. Classification of acute pancreatitis-2012: revision of the Atlanta classification and definitions by international consensus. Gut 2013; 62: $102-111$

92 Loveday BP, Mittal A, Phillips A et al. Minimally invasive management of pancreatic abscess, pseudocyst, and necrosis: a systematic review of current guidelines. World J Surg 2008; 32: 2383-2394

93 Freeman ML, Werner J, van Santvoort HC et al. Interventions for necrotizing pancreatitis: summary of a multidisciplinary consensus conference. Pancreas 2012; 41: 1176-1194

94 van Brunschot S, Bakker OJ, Besselink MG et al. Treatment of necrotizing pancreatitis. Clin Gastroenterol Hepatol 2012; 10: 1190-1201

95 Bello B, Matthews JB. Minimally invasive treatment of pancreatic necrosis. World J Gastroenterol 2012; 18: 6829-6835

96 Akshintala VS, Saxena P, Zaheer A et al. A comparative evaluation of outcomes of endoscopic versus percutaneous drainage for symptomatic pancreatic pseudocysts. Gastrointest Endosc 2014; 79: 921-928; quiz 983 e922, 983 e925

97 Varadarajulu S, Bang JY, Phadnis MA et al. Endoscopic transmural drainage of peripancreatic fluid collections: outcomes and predictors of treatment success in 211 consecutive patients. J Gastrointest Surg 2011; 15: 2080-2088

98 Rische S, Riecken B, Degenkolb J et al. Transmural endoscopic necrosectomy of infected pancreatic necroses and drainage of infected pseudocysts: a tailored approach. Scand J Gastroenterol 2013; 48: 231 - 240
99 van Santvoort HC, Bakker OJ, Bollen TL et al. A conservative and minimally invasive approach to necrotizing pancreatitis improves outcome. Gastroenterology 2011; 141: 1254-1263

100 Tenner S, Baillie J, DeWitt J et al. American College of Gastroenterology guideline: management of acute pancreatitis. Am J Gastroenterol 2013; 108: 1400 - 1415; 1416

101 Schmidt PN, Roug S, Hansen EF et al. Spectrum of microorganisms in infected walled-off pancreatic necrosis - Impact on organ failure and mortality. Pancreatology 2014; 14: 444-449

102 Kotwal V, Talukdar R, Levy $M$ et al. Role of endoscopic ultrasound during hospitalization for acute pancreatitis. World J Gastroenterol 2010; 16: $4888-4891$

103 Rizk MK, Gerke H. Utility of endoscopic ultrasound in pancreatitis: a review. World J Gastroenterol 2007; 13: 6321 -6326

104 Stevens T. Role of endoscopic ultrasonography in the diagnosis of acute and chronic pancreatitis. Gastrointest Endosc Clin N Am 2013; 23: $735-747$

105 De Lisi S, Leandro G, Buscarini E. Endoscopic ultrasonography versus endoscopic retrograde cholangiopancreatography in acute biliary pancreatitis: a systematic review. Eur J Gastroenterol Hepatol 2011 23: $367-374$

106 Petrone MC, Arcidiacono PG, Testoni PA. Endoscopic ultrasonography for evaluating patients with recurrent pancreatitis. World J Gastroenterol 2008; 14: 1016-1022

107 Fusaroli P, Kypraios D, Caletti G et al. Pancreatico-biliary endoscopic ultrasound: a systematic review of the levels of evidence, performance and outcomes. World J Gastroenterol 2012; 18: 4243-4256

108 Morgan DE, Baron TH, Smith JK et al. Pancreatic fluid collections prior to intervention: evaluation with MR imaging compared with CT and US. Radiology 1997; 203: $773-778$

109 Rana SS, Chaudhary V, Sharma R et al. Comparison of abdominal ultrasound, endoscopic ultrasound and magnetic resonance imaging in detection of necrotic debris in walled-off pancreatic necrosis. Gastroenterol Rep (Oxf) 2015, Epub ahead of print

110 Rana SS, Bhasin DK, Sharma RK et al. Do the morphological features of walled off pancreatic necrosis on endoscopic ultrasound determine the outcome of endoscopic transmural drainage? Endosc Ultrasound 2014; 3: $118-122$

111 Hariri M, Slivka A, Carr-Locke DL et al. Pseudocyst drainage predisposes to infection when pancreatic necrosis is unrecognized. Am J Gastroenterol 1994; 89: 1781-1784

112 Jurgensen C, Arlt A, Neser F et al. Endoscopic ultrasound criteria to predict the need for intervention in pancreatic necrosis. BMC Gastroenterol 2012; 12: 48

113 Sarathi Patra P, Das K, Bhattacharyya A et al. Natural resolution or intervention for fluid collections in acute severe pancreatitis. Br J Surg 2014; 101: $1721-1728$

114 Lerch MM, Stier A, Wahnschaffe U et al. Pancreatic pseudocysts: observation, endoscopic drainage, or resection? Dtsch Arztebl Int 2009; 106: $614-621$

115 Besselink MG, van Santvoort HC, Boermeester MA et al. Timing and impact of infections in acute pancreatitis. Br J Surg 2009; 96: 267-273

116 Lankisch PG, Weber-Dany B, Maisonneuve P et al. Pancreatic pseudocysts: prognostic factors for their development and their spontaneous resolution in the setting of acute pancreatitis. Pancreatology 2012; $12: 85-90$

117 Petrov MS, Shanbhag S, Chakraborty $M$ et al. Organ failure and infection of pancreatic necrosis as determinants of mortality in patients with acute pancreatitis. Gastroenterology 2010; 139: 813-820

118 Buchler MW, Gloor B, Muller CA et al. Acute necrotizing pancreatitis: treatment strategy according to the status of infection. Ann Surg 2000; 232: 619-626

119 Rau B, Pralle U, Mayer JM et al. Role of ultrasonographically guided fine-needle aspiration cytology in the diagnosis of infected pancreatic necrosis. Br J Surg 1998; 85: 179-184

120 Negm AA, Poos H, Kruck E et al. Microbiologic analysis of peri-pancreatic fluid collected during EUS in patients with pancreatitis: impact on antibiotic therapy. Gastrointest Endosc 2013; 78: 303-311

121 Jacobson BC, Baron TH, Adler DG et al. ASGE guideline: The role of endoscopy in the diagnosis and the management of cystic lesions and inflammatory fluid collections of the pancreas. Gastrointest Endosc 2005; $61: 363-370$

122 Dumonceau JM, Delhaye M, Tringali A et al. Endoscopic treatment of chronic pancreatitis: European Society of Gastrointestinal Endoscopy (ESGE) Clinical Guideline. Endoscopy 2012; 44: 784-800 
123 Voermans RP, Ponchon T, Schumacher B et al. Forward-viewing versus oblique-viewing echoendoscopes in transluminal drainage of pancreatic fluid collections: a multicenter, randomized, controlled trial. Gastrointest Endosc 2011; 74: 1285-1293

124 Braden B, Dietrich CF. Endoscopic ultrasonography-guided endoscopic treatment of pancreatic pseudocysts and walled-off necrosis: New technical developments. World J Gastroenterol 2014; 20: 16191 - 16196

125 Fabbri C, Luigiano C, Maimone A et al. Endoscopic ultrasound-guided drainage of pancreatic fluid collections. World J Gastrointest Endosc 2012; 4: 479-488

126 Rana SS, Bhasin DK, Rao C et al. Non-fluoroscopic endoscopic ultrasound-guided transmural drainage of symptomatic non-bulging walled-off pancreatic necrosis. Dig Endosc 2013; 25: 47-52

127 Seicean A, Stan-Iuga R, Badea R et al. The safety of endoscopic ultrasonography-guided drainage of pancreatic fluid collections without fluoroscopic control: a single tertiary center experience. J Gastrointestin Liver Dis 2011; 20: 39-45

128 Itoi T, Itokawa F, Tsuchiya $T$ et al. EUS-guided pancreatic pseudocyst drainage: simultaneous placement of stents and nasocystic catheter using double-guidewire technique. Dig Endosc 2009; 21 (Suppl 1): S53-S56

129 Khashab MA, Lennon AM, Singh VK et al. Endoscopic ultrasound (EUS)-guided pseudocyst drainage as a one-step procedure using a novel multiple-wire insertion technique (with video). Surg Endosc 2012; 26: $3320-3323$

130 Ang TL, Teo EK, Fock KM. EUS-guided drainage of infected pancreatic pseudocyst: use of a 10F Soehendra dilator to facilitate a double-wire technique for initial transgastric access (with videos). Gastrointest Endosc 2008; 68: $192-194$

131 Seewald S, Thonke F, Ang TL et al. One-step, simultaneous double-wire technique facilitates pancreatic pseudocyst and abscess drainage (with videos). Gastrointest Endosc 2006; 64: 805-808

132 Binmoeller KF, Weilert F, Shah JN et al. Endosonography-guided transmural drainage of pancreatic pseudocysts using an exchange-free access device: initial clinical experience. Surg Endosc 2013; 27: 1835 1839

133 Voermans RP, Veldkamp MC, Rauws EA et al. Endoscopic transmural debridement of symptomatic organized pancreatic necrosis (with videos). Gastrointest Endosc 2007; 66: 909 -916

134 Committee AT, Desilets DJ, Banerjee $S$ et al. New devices and techniques for management of pancreatic fluid collections. Gastrointest Endosc 2013; 77: $835-838$

135 Lin $H$, Zhan XB, Sun SY et al. Stent selection for endoscopic ultrasound-guided drainage of pancreatic fluid collections: a multicenter study in china. Gastroenterol Res Pract 2014; 2014: 193562

136 Fabbri C, Luigiano C, Cennamo V et al. Endoscopic ultrasound-guided transmural drainage of infected pancreatic fluid collections with placement of covered self-expanding metal stents: a case series. Endoscopy 2012; 44: 429-433

137 Walter D, Will U, Sanchez-Yague A et al. A novel lumen-apposing metal stent for endoscopic ultrasound-guided drainage of pancreatic fluid collections: a prospective cohort study. Endoscopy 2015; 47: 63 -67

138 Sharaiha RZ, DeFilippis EM, Kedia P et al. Metal versus plastic for pancreatic pseudocyst drainage: clinical outcomes and success. Gastrointest Endosc 2015, Epub ahead of print

139 Teoh AY, Ho LK, Dhir VK et al. A multi-institutional survey on the practice of endoscopic ultrasound (EUS) guided pseudocyst drainage in the Asian EUS group. Endosc Int Open 2015; 3: E130-E133

140 Varadarajulu S, Phadnis MA, Christein JD et al. Multiple transluminal gateway technique for EUS-guided drainage of symptomatic walledoff pancreatic necrosis. Gastrointest Endosc 2011; 74: 74-80

141 Siddiqui AA, Dewitt JM, Strongin A et al. Outcomes of EUS-guided drainage of debris-containing pancreatic pseudocysts by using combined endoprosthesis and a nasocystic drain. Gastrointest Endosc 2013; 78: 589-595

142 Varadarajulu S. EUS followed by endoscopic pancreatic pseudocyst drainage or all-in-one procedure: a review of basic techniques (with video). Gastrointest Endosc 2009; 69: S176-S181

143 Heinzow HS, Meister T, Pfromm B et al. Single-step versus multi-step transmural drainage of pancreatic pseudocysts: the use of cystostome is effective and timesaving. Scand J Gastroenterol 2011; 46: 1004- 1013

144 Bang JY, Wilcox CM, Trevino JM et al. Relationship between stent characteristics and treatment outcomes in endoscopic transmural drain- age of uncomplicated pancreatic pseudocysts. Surg Endosc 2014; 28: $2877-2883$

145 Lee BU, Song TJ, Lee SS et al. Newly designed, fully covered metal stents for endoscopic ultrasound (EUS)-guided transmural drainage of peripancreatic fluid collections: a prospective randomized study. Endoscopy 2014; 46: 1078 - 1084

146 Bang JY, Hawes R, Bartolucci A et al. Efficacy of metal and plastic stents for transmural drainage of pancreatic fluid collections: A systematic review. Dig Endosc 2015; 27: 486-498

147 Talreja JP, Shami VM, Ku J et al. Transenteric drainage of pancreaticfluid collections with fully covered self-expanding metallic stents (with video). Gastrointest Endosc 2008; 68: 1199-1203

148 Antillon MR, Bechtold ML, Bartalos CR et al. Transgastric endoscopic necrosectomy with temporary metallic esophageal stent placement for the treatment of infected pancreatic necrosis (with video). Gastrointest Endosc 2009; 69: 178-180

149 Belle $S$, Collet $P$, Post $S$ et al. Temporary cystogastrostomy with self-expanding metallic stents for pancreatic necrosis. Endoscopy 2010; 42: $493-495$

150 Tarantino I, Traina M, Barresi L et al. Transgastric plus transduodenal necrosectomy with temporary metal stents placement for treatment of large pancreatic necrosis. Pancreas 2010; 39: 269-270

151 Berzosa M, Maheshwari S, Patel KK et al. Single-step endoscopic ultrasonography-guided drainage of peripancreatic fluid collections with a single self-expandable metal stent and standard linear echoendoscope. Endoscopy 2012; 44: 543-547

152 Itoi T, Binmoeller KF, Shah J et al. Clinical evaluation of a novel lumenapposing metal stent for endosonography-guided pancreatic pseudocyst and gallbladder drainage (with videos). Gastrointest Endosc 2012; 75: 870-876

153 Krishnan A, Ramakrishnan R. EUS-guided endoscopic necrosectomy and temporary cystogastrostomy for infected pancreatic necrosis with self-expanding metallic stents. Surg Laparosc Endosc Percutan Tech 2012; 22: e319-e321

154 Penn DE, Draganov PV, Wagh MS et al. Prospective evaluation of the use of fully covered self-expanding metal stents for EUS-guided transmural drainage of pancreatic pseudocysts. Gastrointest Endosc 2012; 76: 679-684

155 Weilert F, Binmoeller KF, Shah JN et al. Endoscopic ultrasound-guided drainage of pancreatic fluid collections with indeterminate adherence using temporary covered metal stents. Endoscopy 2012; 44: $780-783$

156 Gornals JB, De la Serna-Higuera C, Sanchez-Yague A et al. Endosonography-guided drainage of pancreatic fluid collections with a novel lumen-apposing stent. Surg Endosc 2013; 27: 1428-1434

157 Itoi T, Nageshwar Reddy D, Yasuda I. New fully-covered self-expandable metal stent for endoscopic ultrasonography-guided intervention in infectious walled-off pancreatic necrosis (with video). J Hepatobiliary Pancreat Sci 2013; 20: $403-406$

158 Yamamoto $N$, Isayama $H$, Kawakami $H$ et al. Preliminary report on a new, fully covered, metal stent designed for the treatment of pancreatic fluid collections. Gastrointest Endosc 2013; 77: 809-814

159 Bapaye A, Itoi T, Kongkam P et al. New fully covered large-bore wideflare removable metal stent for drainage of pancreatic fluid collections: Results of a multicenter study. Dig Endosc 2015; 27: 499-504

160 Saxena $P$, Singh VK, Messallam A et al. Resolution of walled-off pancreatic necrosis by EUS-guided drainage when using a fully covered through-the-scope self-expandable metal stent in a single procedure (with video). Gastrointest Endosc 2014; 80: 319-324

161 Rinninella $E$, Kunda R, Dollhopf $M$ et al. EUS-guided drainage of pancreatic fluid collections using a novel lumen-apposing metal stent on an electrocautery-enhanced delivery system: a large retrospective study (with video). Gastrointest Endosc 2015, Epub ahead of print

162 Huggett MT, Oppong KW, Pereira SP et al. Endoscopic drainage of walled-off pancreatic necrosis using a novel self-expanding metal stent. Endoscopy 2015, Epub ahead of print

163 Rosso E, Alexakis N, Ghaneh P et al. Pancreatic pseudocyst in chronic pancreatitis: endoscopic and surgical treatment. Dig Surg 2003; 20: $397-406$

164 Varadarajulu S, Lopes TL, Wilcox CM et al. EUS versus surgical cystgastrostomy for management of pancreatic pseudocysts. Gastrointest Endosc 2008; 68: 649-655

165 Varadarajulu S, Bang JY, Sutton BS et al. Equal efficacy of endoscopic and surgical cystogastrostomy for pancreatic pseudocyst drainage in a randomized trial. Gastroenterology 2013; 145: 583 - 590 e581 
166 Aghdassi A, Mayerle J, Kraft M et al. Diagnosis and treatment of pancreatic pseudocysts in chronic pancreatitis. Pancreas 2008; 36: 105 112

167 Guenther L, Hardt PD, Collet P. Review of current therapy of pancreatic pseudocysts. Z Gastroenterol 2015; 53: 125 - 135

168 Binmoeller KF, Seifert $H$, Walter A et al. Transpapillary and transmural drainage of pancreatic pseudocysts. Gastrointest Endosc 1995; 42: $219-224$

169 Barthet M, Lamblin G, Gasmi M et al. Clinical usefulness of a treatment algorithm for pancreatic pseudocysts. Gastrointest Endosc 2008; 67: $245-252$

170 Hookey LC, Debroux S, Delhaye M et al. Endoscopic drainage of pancreatic-fluid collections in 116 patients: a comparison of etiologies, drainage techniques, and outcomes. Gastrointest Endosc 2006; 63: $635-643$

171 Fabbri C, Luigiano C, Lisotti A et al. Endoscopic ultrasound-guided treatments: are we getting evidence based-a systematic review. World J Gastroenterol 2014; 20: 8424-8448

172 Hocke $M$, Will $U$, Gottschalk $P$ et al. Transgastral retroperitoneal endoscopy in septic patients with pancreatic necrosis or infected pancreatic pseudocysts. Z Gastroenterol 2008; 46: 1363-1368

173 Will $U$, Wanzar $C$, Gerlach $R$ et al. Interventional ultrasound-guided procedures in pancreatic pseudocysts, abscesses and infected necroses - treatment algorithm in a large single-center study. Ultraschall in Med 2011; 32: 176-183

174 Kahaleh M, Shami VM, Conaway MR et al. Endoscopic ultrasound drainage of pancreatic pseudocyst: a prospective comparison with conventional endoscopic drainage. Endoscopy 2006; 38: 355 - 359

175 Varadarajulu S, Wilcox CM, Tamhane A et al. Role of EUS in drainage of peripancreatic fluid collections not amenable for endoscopic transmural drainage. Gastrointest Endosc 2007; 66: 1107-1119

176 Park DH, Lee SS, Moon SH et al. Endoscopic ultrasound-guided versus conventional transmural drainage for pancreatic pseudocysts: a prospective randomized trial. Endoscopy 2009; 41: 842-848

177 Varadarajulu S, Christein JD, Tamhane A et al. Prospective randomized trial comparing EUS and EGD for transmural drainage of pancreatic pseudocysts (with videos). Gastrointest Endosc 2008; 68: 1102 1111

178 Panamonta N, Ngamruengphong S, Kijsirichareanchai K et al. Endoscopic ultrasound-guided versus conventional transmural techniques have comparable treatment outcomes in draining pancreatic pseudocysts. Eur J Gastroenterol Hepatol 2012; 24: 1355-1362

179 Jagielski M, Smoczynski M, Jablonska A et al. The role of endoscopic ultrasonography in endoscopic debridement of walled-off pancreatic necrosis - A single center experience. Pancreatology 2015, Epub ahead of print

180 van Santvoort HC, Besselink MG, Bakker OJ et al. A step-up approach or open necrosectomy for necrotizing pancreatitis. N Engl J Med 2010; 362: $1491-1502$

181 van Baal MC, van Santvoort HC, Bollen TL et al. Systematic review of percutaneous catheter drainage as primary treatment for necrotizing pancreatitis. Br J Surg 2011; 98: 18 - 27

182 Bakker OJ, van Santvoort HC, van Brunschot S et al. Endoscopic transgastric vs surgical necrosectomy for infected necrotizing pancreatitis: a randomized trial. JAMA 2012; 307: 1053-1061

183 Baron TH, Harewood GC, Morgan DE et al. Outcome differences after endoscopic drainage of pancreatic necrosis, acute pancreatic pseudocysts, and chronic pancreatic pseudocysts. Gastrointest Endosc 2002; 56: $7-17$

184 Gardner TB, Chahal P, Papachristou GI et al. A comparison of direct endoscopic necrosectomy with transmural endoscopic drainage for the treatment of walled-off pancreatic necrosis. Gastrointest Endosc 2009; 69: 1085 - 1094

185 Puli SR, Graumlich JF, Pamulaparthy SR et al. Endoscopic transmural necrosectomy for walled-off pancreatic necrosis: a systematic review and meta-analysis. Can J Gastroenterol Hepatol 2014; 28: 50-53

186 van Brunschot S, Fockens P, Bakker OJ et al. Endoscopic transluminal necrosectomy in necrotising pancreatitis: a systematic review. Surg Endosc 2014; 28: 1425 - 1438

187 da Costa DW, Boerma D, van Santvoort HC et al. Staged multidisciplinary step-up management for necrotizing pancreatitis. Br J Surg 2014; 101: e65-e79

188 Bang JY, Holt BA, Hawes RH et al. Outcomes after implementing a tailored endoscopic step-up approach to walled-off necrosis in acute pancreatitis. Br J Surg 2014; 101: 1729-1738
189 Gardner TB, Coelho-Prabhu N, Gordon SR et al. Direct endoscopic necrosectomy for the treatment of walled-off pancreatic necrosis: results from a multicenter U.S. series. Gastrointest Endosc 2011; 73 : $718-726$

190 Seifert H, Biermer M, Schmitt W et al. Transluminal endoscopic necrosectomy after acute pancreatitis: a multicentre study with long-term follow-up (the GEPARD Study). Gut 2009; 58: 1260 - 1266

191 Yasuda I, Nakashima M, Iwai T et al. Japanese multicenter experience of endoscopic necrosectomy for infected walled-off pancreatic necrosis: The JENIPaN study. Endoscopy 2013; 45: 627-634

192 Gluck M, Ross A, Irani S et al. Dual modality drainage for symptomatic walled-off pancreatic necrosis reduces length of hospitalization, radiological procedures, and number of endoscopies compared to standard percutaneous drainage. J Gastrointest Surg 2012; 16: 248 256; discussion 256-247

193 Gluck M, Ross A, Irani S et al. Endoscopic and percutaneous drainage of symptomatic walled-off pancreatic necrosis reduces hospital stay and radiographic resources. Clin Gastroenterol Hepatol 2010; 8: $1083-1088$

194 Ross A, Gluck M, Irani S et al. Combined endoscopic and percutaneous drainage of organized pancreatic necrosis. Gastrointest Endosc 2010; 71: $79-84$

195 Ross AS, Irani S, Gan SI et al. Dual-modality drainage of infected and symptomatic walled-off pancreatic necrosis: long-term clinical outcomes. Gastrointest Endosc 2014; 79: 929-935

196 Bang JY, Wilcox CM, Trevino J et al. Factors impacting treatment outcomes in the endoscopic management of walled-off pancreatic necrosis. J Gastroenterol Hepatol 2013; 28: 1725-1732

197 Mukai S, Itoi T, Sofuni A et al. Expanding endoscopic interventions for pancreatic pseudocyst and walled-off necrosis. J Gastroenterol 2015 50: $211-220$

198 Cahen D, Rauws E, Fockens $P$ et al. Endoscopic drainage of pancreatic pseudocysts: long-term outcome and procedural factors associated with safe and successful treatment. Endoscopy 2005; 37: 977-983

199 Rana SS, Bhasin DK, Rao C et al. Consequences of long term indwelling transmural stents in patients with walled off pancreatic necrosis \& disconnected pancreatic duct syndrome. Pancreatology 2013; 13: $486-490$

200 Arvanitakis M, Delhaye M, Bali MA et al. Pancreatic-fluid collections: a randomized controlled trial regarding stent removal after endoscopic transmural drainage. Gastrointest Endosc 2007; 65: 609-619

201 Dhir V, Teoh AY, Bapat $M$ et al. EUS-guided pseudocyst drainage: prospective evaluation of early removal of fully covered self-expandable metal stents with pancreatic ductal stenting in selected patients. Gastrointest Endosc 2015; 82: 650 - 657

202 Rasmussen DN, Hassan H, Vilmann P. Only few severe complications after endoscopic ultrasound guided drainage of pancreatic pseudocysts. Dan Med J 2012; 59: A4406

$203 \mathrm{Ng}$ PY, Rasmussen DN, Vilmann P et al. Endoscopic Ultrasound-guided Drainage of Pancreatic Pseudocysts: Medium-Term Assessment of Outcomes and Complications. Endosc Ultrasound 2013; 2: 199-203

204 Sanchez Cortes E, Maalak A, Le Moine O et al. Endoscopic cystenterostomy of nonbulging pancreatic fluid collections. Gastrointest Endosc 2002: $56: 380-386$

205 Fockens P, Johnson TG, van Dullemen HM et al. Endosonographic imaging of pancreatic pseudocysts before endoscopic transmural drainage. Gastrointest Endosc 1997; 46: $412-416$

206 Smits ME, Rauws EA, Tytgat GN et al. The efficacy of endoscopic treatment of pancreatic pseudocysts. Gastrointest Endosc 1995; 42: 202 207

207 Kruger M, Schneider AS, Manns MP et al. Endoscopic management of pancreatic pseudocysts or abscesses after an EUS-guided 1-step procedure for initial access. Gastrointest Endosc 2006; 63: 409-416

208 De Palma GD, Galloro G, Puzziello A et al. Endoscopic drainage of pancreatic pseudocysts: a long-term follow-up study of 49 patients. Hepatogastroenterology 2002; 49: 1113-1115

209 Bonnot B, Nion-Larmurier I, Desaint B et al. Fatal gas embolism after endoscopic transgastric necrosectomy for infected necrotizing pancreatitis. Am J Gastroenterol 2014; 109: 607-608

210 Haghshenasskashani A, Laurence JM, Kwan V et al. Endoscopic necrosectomy of pancreatic necrosis: a systematic review. Surg Endosc 2011; 25: 3724-3730

211 Tilara A, Gerdes H, Allen P et al. Endoscopic ultrasound-guided transmural drainage of postoperative pancreatic collections. J Am Coll Surg 2014; 218: 33-40 
212 Wehrmann T, Stergiou N, Vogel B et al. Endoscopic debridement of paraesophageal, mediastinal abscesses: a prospective case series. Gastrointest Endosc 2005; 62: 344 - 349

213 Consiglieri CF, Escobar I, Gornals JB. EUS-guided transesophageal drainage of a mediastinal abscess using a diabolo-shaped lumen-apposing metal stent. Gastrointest Endosc 2015; 81: 221 - 222

214 Saxena $P$, Kumbhari V, Khashab MA. EUS-guided drainage of a mediastinal abscess. Gastrointest Endosc 2014; 79: 998-999

215 Varadarajulu S, Eloubeidi MA, Wilcox CM. The concept of bedside EUS. Gastrointest Endosc 2008; 67: 1180-1184

216 Prasad GA, Varadarajulu S. Endoscopic ultrasound-guided abscess drainage. Gastrointest Endosc Clin N Am 2012; 22: 281 - 290, ix

217 Noh SH, Park do H, Kim YR et al. EUS-guided drainage of hepatic abscesses not accessible to percutaneous drainage (with videos). Gastrointest Endosc 2010; 71: 1314-1319

218 Itoi T, Ang TL, Seewald $S$ et al. Endoscopic ultrasonography-guided drainage for tuberculous liver abscess drainage. Dig Endosc 2011; 23 (Suppl 1): 158-161

219 Ang TL, Seewald S, Teo EK et al. EUS-guided drainage of ruptured liver abscess. Endoscopy 2009; 41 (Suppl 2): E21 - E22

220 Seewald S, Brand B, Omar $S$ et al. EUS-guided drainage of subphrenic abscess. Gastrointest Endosc 2004; 59: 578- 580

221 Seewald S, Imazu H, Omar S et al. EUS-guided drainage of hepatic abscess. Gastrointest Endosc 2005; 61: 495 - 498

222 Lee DH, Cash BD, Womeldorph CM et al. Endoscopic therapy of a splenic abscess: definitive treatment via EUS-guided transgastric drainage. Gastrointest Endosc 2006; 64: 631 - 634

223 Alcaide N, Vargas-Garcia AL, de la Serna-Higuera $C$ et al. EUS-guided drainage of liver abscess by using a lumen-apposing metal stent (with video). Gastrointest Endosc 2013; 78: 941 - 942; discussion 942

224 Holt B, Varadarajulu $S$. Endoscopic ultrasound-guided pelvic abscess drainage (with video). J Hepatobiliary Pancreat Sci 2015; 22: 12-15

225 Hadithi M, Bruno MJ. Endoscopic ultrasound-guided drainage of pelvic abscess: A case series of 8 patients. World J Gastrointest Endosc 2014; 6: $373-378$

226 Puri R, Choudhary NS, Kotecha H et al. Endoscopic ultrasound-guided pelvic and prostatic abscess drainage: experience in 30 patients. Indian J Gastroenterol 2014; 33: 410-413

227 Puri R, Eloubeidi MA, Sud R et al. Endoscopic ultrasound-guided drainage of pelvic abscess without fluoroscopy guidance. J Gastroenterol Hepatol 2010; 25: 1416 - 1419

228 Puri R, Jain P, Sud R et al. EUS-guided drainage of an isolated primary tubercular prostatic abscess. Gastrointest Endosc 2010; 71: 425 - 428

229 Fernandez-Urien I, Vila JJ, Jimenez FJ. Endoscopic ultrasound-guided drainage of pelvic collections and abscesses. World J Gastrointest Endosc 2010; 2: 223-227

230 Varadarajulu S, Drelichman ER. Effectiveness of EUS in drainage of pelvic abscesses in 25 consecutive patients (with video). Gastrointest Endosc 2009; 70: 1121 - 1127

231 Varadarajulu S, Drelichman ER. EUS-guided drainage of pelvic abscess (with video). Gastrointest Endosc 2007; 66: 372 - 376

232 Giovannini $M$, Bories E, Moutardier $V$ et al. Drainage of deep pelvic abscesses using therapeutic echo endoscopy. Endoscopy 2003; 35 : $511-514$

233 Ramesh J, Bang JY, Trevino J et al. Comparison of outcomes between endoscopic ultrasound-guided transcolonic and transrectal drainage of abdominopelvic abscesses. J Gastroenterol Hepatol 2013; 28: 620 625

234 Ulla-Rocha JL, Vilar-Cao Z, Sardina-Ferreiro R. EUS-guided drainage and stent placement for postoperative intra-abdominal and pelvic fluid collections in oncological surgery. Therap Adv Gastroenterol 2012; 5: 95-102

235 Piraka C, Shah RJ, Fukami N et al. EUS-guided transesophageal, transgastric, and transcolonic drainage of intra-abdominal fluid collections and abscesses. Gastrointest Endosc 2009; 70: 786-792

236 Shami VM, Talreja JP, Mahajan A et al. EUS-guided drainage of bilomas: a new alternative? Gastrointest Endosc 2008; 67: 136-140

237 Decker C, Varadarajulu S. EUS-guided drainage of an intra-abdominal abscess after liver transplantation. Gastrointest Endosc 2011; 73: 1056 - 1058

238 Adler DG, Baron TH, Davila RE et al. ASGE guideline: the role of ERCP in diseases of the biliary tract and the pancreas. Gastrointest Endosc $2005 ; 62: 1-8$
239 Carr-Locke DL. Overview of the role of ERCP in the management of diseases of the biliary tract and the pancreas. Gastrointest Endosc 2002; 56: S157-S160

240 Farrell J, Carr-Locke D, Garrido T et al. Endoscopic retrograde cholangiopancreatography after pancreaticoduodenectomy for benign and malignant disease: indications and technical outcomes. Endoscopy 2006; 38: $1246-1249$

241 Schofl $R$. Diagnostic endoscopic retrograde cholangiopancreatography. Endoscopy 2001; 33: 147 - 157

242 Ponchon T. Diagnostic endoscopic retrograde cholangiopancreatography. Endoscopy 2000; 32: $200-208$

243 DeBenedet AT, Elmunzer BJ, McCarthy ST et al. Intraprocedural quality in endoscopic retrograde cholangiopancreatography: a meta-analysis. Am J Gastroenterol 2013; 108: 1696-1704; quiz 1705

244 Andriulli $A$, Loperfido $S$, Napolitano $G$ et al. Incidence rates of postERCP complications: a systematic survey of prospective studies. Am J Gastroenterol 2007; 102: 1781 - 1788

245 Anderson MA, Fisher L, Jain R. Committee ASoP. et al. Complications of ERCP. Gastrointest Endosc 2012; 75: 467 - 473

246 Freeman ML. Complications of endoscopic retrograde cholangiopancreatography: avoidance and management. Gastrointest Endosc Clin N Am 2012; 22: $567-586$

247 Doctor N, Dick R, Rai R et al. Results of percutaneous plastic stents for malignant distal biliary obstruction following failed endoscopic stent insertion and comparison with current literature on expandable metallic stents. Eur J Gastroenterol Hepatol 1999; 11: 775-780

248 van Delden OM, Lameris JS. Percutaneous drainage and stenting for palliation of malignant bile duct obstruction. Eur Radiol 2008; 18 : 448-456

249 Beissert M, Wittenberg G, Sandstede J et al. Metallic stents and plastic endoprostheses in percutaneous treatment of biliary obstruction. Z Gastroenterol 2002; 40: 503-510

250 Kuhn JP, Busemann A, Lerch MM et al. Percutaneous biliary drainage in patients with nondilated intrahepatic bile ducts compared with patients with dilated intrahepatic bile ducts. Am J Roentgenol Am J Roentgenol 2010; 195: $851-857$

251 Winick $A B$, Waybill PN, Venbrux AC. Complications of percutaneous transhepatic biliary interventions. Tech Vasc Interv Radiol 2001; 4 : 200-206

252 Covey AM, Brown KT. Percutaneous transhepatic biliary drainage Tech Vasc Interv Radiol 2008; 11: 14-20

253 Brown KT, Covey AM. Management of malignant biliary obstruction. Tech Vasc Interv Radiol 2008; 11: $43-50$

254 Weber A, Gaa J, Rosca B et al. Complications of percutaneous transhepatic biliary drainage in patients with dilated and nondilated intrahepatic bile ducts. Eur J Radiol 2009; 72: 412-417

255 Mueller PR, van Sonnenberg E, Ferrucci JT et al. Percutaneous biliary drainage: technical and catheter-related problems in 200 procedures. Am J Roentgenol Am J Roentgenol 1982; 138: 17-23

256 Spanheimer PM, Cyr AR, Liao J et al. Complications and survival associated with operative procedures in patients with unresectable pancreatic head adenocarcinoma. J Surg Oncol 2014; 109: 697-701

257 Sohn TA, Lillemoe KD, Cameron JL et al. Surgical palliation of unresectable periampullary adenocarcinoma in the 1990s. J Am Coll Surg 1999; 188: 658-666; discussion 666-659

258 Luu C, Lee B, Stabile BE. Choledochoduodenostomy as the biliary-enteric bypass of choice for benign and malignant distal common bile duct strictures. Am Surg 2013; 79: 1054-1057

259 Wiersema MJ, Sandusky D, Carr R et al. Endosonography-guided cholangiopancreatography. Gastrointest Endosc 1996; 43: $102-106$

260 Giovannini M, Moutardier V, Pesenti C et al. Endoscopic ultrasoundguided bilioduodenal anastomosis: a new technique for biliary drainage. Endoscopy 2001; 33: 898-900

261 Burmester E, Niehaus J, Leineweber $T$ et al. EUS-cholangio-drainage of the bile duct: report of 4 cases. Gastrointest Endosc 2003; 57: 246-251

262 Mallery S, MatlockJ, Freeman ML. EUS-guided rendezvous drainage of obstructed biliary and pancreatic ducts: Report of 6 cases. Gastrointest Endosc 2004; 59: 100-107

263 Dhir V, Bhandari S, Bapat $M$ et al. Comparison of EUS-guided rendezvous and precut papillotomy techniques for biliary access (with videos). Gastrointest Endosc 2012; 75: 354 - 359

264 Park do H, Jang JW, Lee SS et al. EUS-guided biliary drainage with transluminal stenting after failed ERCP: predictors of adverse events and long-term results. Gastrointest Endosc 2011; 74: 1276-1284 
265 Will U, Fueldner F, Kern C et al. EUS-Guided Bile Duct Drainage (EUBD) in 95 Patients. Ultraschall in Med 2015; 36: 276-283

266 Itoi T, Sofuni A, Tsuchiya T et al. Endoscopic ultrasonography-guided transhepatic antegrade stone removal in patients with surgically altered anatomy: case series and technical review (with videos). J Hepatobiliary Pancreat Sci 2014; 21: E86 - E93

267 Gupta K, Perez-Miranda M, Kahaleh M et al. Endoscopic ultrasoundassisted bile duct access and drainage: multicenter, long-term analysis of approach, outcomes, and complications of a technique in evolution. J Clin Gastroenterol 2014; 48: 80-87

268 Kahaleh M, Artifon EL, Perez-Miranda M et al. Endoscopic ultrasonography guided biliary drainage: summary of consortium meeting, May 7th, 2011, Chicago. World J Gastroenterol 2013; 19: 1372 - 1379

269 Prichard D, Byrne MF. Endoscopic ultrasound guided biliary and pancreatic duct interventions. World J Gastrointest Endosc 2014; 6: $513-524$

270 Sarkaria S, Sundararajan S, Kahaleh M. Endoscopic ultrasonographic access and drainage of the common bile duct. Gastrointest Endosc Clin N Am 2013; 23: 435-452

271 Maranki J, Hernandez AJ, Arslan B et al. Interventional endoscopic ultrasound-guided cholangiography: long-term experience of an emerging alternative to percutaneous transhepatic cholangiography. Endoscopy 2009; 41: $532-538$

272 Iwashita T, Doi S, Yasuda I. Endoscopic ultrasound-guided biliary drainage: a review. Clin J Gastroenterol 2014; 7: 94-102

273 Kedia P, Gaidhane M, Kahaleh M. Endoscopic guided biliary drainage: how can we achieve efficient biliary drainage? Clin Endosc 2013; 46: $543-551$

274 Artifon EL, Aparicio D, Paione JB et al. Biliary drainage in patients with unresectable, malignant obstruction where ERCP fails: endoscopic ultrasonography-guided choledochoduodenostomy versus percutaneous drainage. J Clin Gastroenterol 2012; 46: 768 - 774

275 Bapaye A, Dubale N, Aher A. Comparison of endosonography-guided vs. percutaneous biliary stenting when papilla is inaccessible for ERCP. United European Gastroenterol J 2013; 1: 285 - 293

276 Khashab MA, Valeshabad AK, Afghani E et al. A Comparative Evaluation of EUS-Guided Biliary Drainage and Percutaneous Drainage in Patients with Distal Malignant Biliary Obstruction and Failed ERCP. Dig Dis Sci 2015: 60: $557-565$

277 Dhir V, Itoi T, Khashab MA et al. Multicenter comparative evaluation of endoscopic placement of expandable metal stents for malignant distal common bile duct obstruction by ERCP or EUS-guided approach. Gastrointest Endosc 2015; 81: 913 - 923

278 Iwashita T, Lee JG, Shinoura S et al. Endoscopic ultrasound-guided rendezvous for biliary access after failed cannulation. Endoscopy 2012; 44: 60-65

279 Shah JN, Marson F, Weilert F et al. Single-operator, single-session EUSguided anterograde cholangiopancreatography in failed ERCP or inaccessible papilla. Gastrointest Endosc 2012; 75: 56-64

280 Park do H, Jeong SU, Lee BU et al. Prospective evaluation of a treatment algorithm with enhanced guidewire manipulation protocol for EUSguided biliary drainage after failed ERCP (with video). Gastrointest Endosc 2013; 78: 91 - 101

281 Nguyen-Tang T, Binmoeller KF, Sanchez-Yague A et al. Endoscopic ultrasound (EUS)-guided transhepatic anterograde self-expandable metal stent (SEMS) placement across malignant biliary obstruction. Endoscopy 2010; 42: 232-236

282 Ogura T, Masuda D, Imoto A et al. EUS-guided hepaticogastrostomy combined with fine-gauge antegrade stenting: a pilot study. Endoscopy 2014; 46: 416-421

283 Fabbri C, Luigiano C, Fuccio L et al. EUS-guided biliary drainage with placement of a new partially covered biliary stent for palliation of malignant biliary obstruction: a case series. Endoscopy 2011; 43: $438-441$

284 Dhir V, Artifon EL, Gupta K et al. Multicenter study on endoscopic ultrasound-guided expandable biliary metal stent placement: choice of access route, direction of stent insertion, and drainage route. Dig Endosc 2014; $26: 430-435$

285 Dhir V, Itoi T, Khashab MA et al. Multicenter comparative evaluation of endoscopic placement of expandable metal stents for malignant distal common bile duct obstruction by ERCP or EUS-guided approach. Gastrointest Endosc 2015; 81: 913 -923

286 Song TJ, Lee SS, Park do $H$ et al. Preliminary report on a new hybrid metal stent for EUS-guided biliary drainage (with videos). Gastrointest Endosc 2014; 80: 707-711
287 Lee TH, Choi JH, Lee SS et al. A pilot proof-of-concept study of a modified device for one-step endoscopic ultrasound-guided biliary drainage in a new experimental biliary dilatation animal model. World J Gastroenterol 2014; 20: 5859-5866

288 Park DH, Lee TH, Paik WH et al. Feasibility and safety of a novel dedicated device for one-step EUS-guided biliary drainage: a randomized trial. J Gastroenterol Hepatol 2015; 30: 1461 - 1466

289 Vila JJ, Perez-Miranda M, Vazquez-Sequeiros E et al. Initial experience with EUS-guided cholangiopancreatography for biliary and pancreatic duct drainage: a Spanish national survey. Gastrointest Endosc 2012; 76: 1133-1141

290 Iwashita T, Lee JG. Endoscopic ultrasonography-guided biliary drainage: rendezvous technique. Gastrointest Endosc Clin N Am 2012; 22: 249-258, viii-ix

291 Isayama H, Nakai Y, Kawakubo K et al. The endoscopic ultrasonography-guided rendezvous technique for biliary cannulation: a technical review. J Hepatobiliary Pancreat Sci 2013; 20: 413-420

292 Dhir V, Bhandari S, Bapat M et al. Comparison of transhepatic and extrahepatic routes for EUS-guided rendezvous procedure for distal CBD obstruction. United European Gastroenterol J 2013; 1: 103-108

293 Khashab MA, Valeshabad AK, Modayil $R$ et al. EUS-guided biliary drainage by using a standardized approach for malignant biliary obstruction: rendezvous versus direct transluminal techniques (with videos). Gastrointest Endosc 2013; 78: 734-741

294 Artifon EL, Marson FP, Gaidhane M et al. Hepaticogastrostomy or choledochoduodenostomy for distal malignant biliary obstruction after failed ERCP: Is there any difference? Gastrointest Endosc 2015; 81 950-959

295 Poincloux L, Rouquette O, Buc E et al. Endoscopic ultrasound-guided biliary drainage after failed ERCP: cumulative experience of 101 procedures at a single center. Endoscopy 2015; 47: 794-801

296 Kawakubo K, Isayama $\mathrm{H}$, Kato $\mathrm{H}$ et al. Multicenter retrospective study of endoscopic ultrasound-guided biliary drainage for malignant biliary obstruction in Japan. J Hepatobiliary Pancreat Sci 2014; 21 : $328-334$

$297 \mathrm{Kim}$ TH, Kim SH, Oh HJ et al. Endoscopic ultrasound-guided biliary drainage with placement of a fully covered metal stent for malignant biliary obstruction. World J Gastroenterol 2012; 18: 2526-2532

298 Song TJ, Hyun YS, Lee SS et al. Endoscopic ultrasound-guided choledochoduodenostomies with fully covered self-expandable metallic stents. World J Gastroenterol 2012; 18: 4435 - 4440

299 Sarkaria S, Lee HS, Gaidhane M et al. Advances in endoscopic ultrasound-guided biliary drainage: a comprehensive review. Gut Liver 2013; 7: 129-136

300 Penas-Herrero I, de la Serna-Higuera C, Perez-Miranda M. Endoscopic ultrasound-guided gallbladder drainage for the management of acute cholecystitis (with video). J Hepatobiliary Pancreat Sci 2015; 22: 35-43

301 Baron TH, Topazian MD. Endoscopic transduodenal drainage of the gallbladder: implications for endoluminal treatment of gallbladder disease. Gastrointest Endosc 2007; 65: 735 - 737

302 Kwan V, Eisendrath P, Antaki $F$ et al. EUS-guided cholecystenterostomy: a new technique (with videos). Gastrointest Endosc 2007; 66: $582-586$

303 Jang JW, Lee SS, Park do H et al. Feasibility and safety of EUS-guided transgastric/transduodenal gallbladder drainage with single-step placement of a modified covered self-expandable metal stent in patients unsuitable for cholecystectomy. Gastrointest Endosc 2011; 74: $176-181$

304 Lee SS, Park do H, Hwang CY et al. EUS-guided transmural cholecystostomy as rescue management for acute cholecystitis in elderly or high-risk patients: a prospective feasibility study. Gastrointest Endosc 2007; 66: 1008 - 1012

305 Song TJ, Park do H, Eum JB et al. EUS-guided cholecystoenterostomy with single-step placement of a $7 \mathrm{~F}$ double-pigtail plastic stent in patients who are unsuitable for cholecystectomy: a pilot study (with video). Gastrointest Endosc 2010; 71: 634-640

306 Moon JH, Choi HJ, Kim DC et al. A newly designed fully covered metal stent for lumen apposition in EUS-guided drainage and access: a feasibility study (with videos). Gastrointest Endosc 2014; 79: 990 - 995

307 Choi JH, Lee SS, Choi JH et al. Long-term outcomes after endoscopic ultrasonography-guided gallbladder drainage for acute cholecystitis. Endoscopy 2014; 46: 656-661

308 Irani S, Baron TH, Grimm IS et al. EUS-guided gallbladder drainage with a lumen-apposing metal stent (with video). Gastrointest Endosc 2015, Epub ahead of print 
309 Walter D, Teoh AY, Itoi T et al. EUS-guided gall bladder drainage with a lumen-apposing metal stent: a prospective long-term evaluation. Gut 2015, Epub ahead of print

310 Jang JW, Lee SS, Song TJ et al. Endoscopic ultrasound-guided transmural and percutaneous transhepatic gallbladder drainage are comparable for acute cholecystitis. Gastroenterology 2012; 142: 805 811

311 Cahen DL, Gouma DJ, Nio Y et al. Endoscopic versus surgical drainage of the pancreatic duct in chronic pancreatitis. N Engl J Med 2007; 356: $676-684$

312 Dite P, Ruzicka M, Zboril V et al. A prospective, randomized trial comparing endoscopic and surgical therapy for chronic pancreatitis. Endoscopy 2003; 35: $553-558$

313 Harada N, Kouzu T, Arima M et al. Endoscopic ultrasound-guided pancreatography: a case report. Endoscopy 1995; 27: 612-615

314 Fujii-Lau LL, Levy MJ. Endoscopic ultrasound-guided pancreatic duct drainage. J Hepatobiliary Pancreat Sci 2015; 22: 51 - 57

315 Fujii LL, Topazian MD, Abu Dayyeh BK et al. EUS-guided pancreatic duct intervention: outcomes of a single tertiary-care referral center experience. Gastrointest Endosc 2013; 78: 854 - 864 e851

316 Jenssen C, Kahl S. Management of incidental cystic pancreatic lesions. Viszeralmedizin 2015; 31: 14-24

317 Oh HC, Brugge WR. EUS-guided pancreatic cyst ablation: a critical review (with video). Gastrointest Endosc 2013; 77: 526-533

318 Gan SI, Thompson CC, Lauwers GY et al. Ethanol lavage of pancreatic cystic lesions: initial pilot study. Gastrointest Endosc 2005; 61: $746-752$

319 DeWitt J, McGreevy K, Schmidt CM et al. EUS-guided ethanol versus saline solution lavage for pancreatic cysts: a randomized, doubleblind study. Gastrointest Endosc 2009; 70: 710 - 723

320 DeWitt J, DiMaio CJ, Brugge WR. Long-term follow-up of pancreatic cysts that resolve radiologically after EUS-guided ethanol ablation. Gastrointest Endosc 2010; 72: 862-866

321 DiMaio CJ, DeWitt JM, Brugge WR. Ablation of pancreatic cystic lesions: the use of multiple endoscopic ultrasound-guided ethanol lavage sessions. Pancreas 2011; 40: 664-668

322 Caillol F, Poincloux L, Bories $E$ et al. Ethanol lavage of 14 mucinous cysts of the pancreas: A retrospective study in two tertiary centers. Endosc Ultrasound 2012; 1:48-52

323 Oh HC, Seo DW, Lee TY et al. New treatment for cystic tumors of the pancreas: EUS-guided ethanol lavage with paclitaxel injection. Gastrointest Endosc 2008; 67: 636-642

324 Oh HC, Seo DW, Song TJ et al. Endoscopic ultrasonography-guided ethanol lavage with paclitaxel injection treats patients with pancreatic cysts. Gastroenterology 2011; 140: 172 - 179

325 Oh HC, Seo DW, Kim SC et al. Septated cystic tumors of the pancreas: is it possible to treat them by endoscopic ultrasonography-guided intervention? Scand J Gastroenterol 2009; 44: 242 - 247

326 DeWitt JM, Al-Haddad M, Sherman S et al. Alterations in cyst fluid genetics following endoscopic ultrasound-guided pancreatic cyst ablation with ethanol and paclitaxel. Endoscopy 2014; 46: 457-464

327 Oh HC, Seo DW, Kim SH et al. Systemic effect of endoscopic ultrasonography-guided pancreatic cyst ablation with ethanol and paclitaxel. Dig Dis Sci 2014; 59: 1573 - 1577

328 Kandula M, Moole H, Cashman $M$ et al. Success of endoscopic ultrasound-guided ethanol ablation of pancreatic cysts: A meta-analysis and systematic review. Indian J Gastroenterol 2015; 34: 193 - 199

329 Oh HC, Seo DW, Kim SC. Portal vein thrombosis after EUS-guided pancreatic cyst ablation. Dig Dis Sci 2012; 57: 1965-1967

330 Jurgensen $C$, Schuppan D, Neser F et al. EUS-guided alcohol ablation of an insulinoma. Gastrointest Endosc 2006; 63: 1059-1062

331 Deprez PH, Claessens A, Borbath I et al. Successful endoscopic ultrasound-guided ethanol ablation of a sporadic insulinoma. Acta Gastroenterol Belg 2008; 71: 333 - 337

332 Vleggaar FP, Bij de Vaate EA, Valk GD et al. Endoscopic ultrasoundguided ethanol ablation of a symptomatic sporadic insulinoma. Endoscopy 2011; 43 (Suppl 2): UCTN:E328 - E329

333 Levy MJ, Thompson GB, Topazian MD et al. US-guided ethanol ablation of insulinomas: a new treatment option. Gastrointest Endosc 2012; 75: $200-206$

334 Qin SY, Lu XP, Jiang HX. EUS-guided ethanol ablation of insulinomas: case series and literature review. Medicine (Baltimore) 2014; 93: e85

335 Bor R, Farkas K, Balint A et al. Endoscopic ultrasound-guided ethanol ablation: an alternative option for the treatment of pancreatic insulinoma. Orv Hetil 2014; 155: 1647 - 1651
336 Matthes K, Mino-Kenudson M, Sahani DV et al. Concentration-dependent ablation of pancreatic tissue by EUS-guided ethanol injection. Gastrointest Endosc 2007; 65: 272-277

337 Sahani DV, Holalkere NS, Kambadakone A et al. Role of computed tomography perfusion in the evaluation of pancreatic necrosis and pancreatitis after endoscopic ultrasound-guided ablation of the pancreas in a porcine model. Pancreas 2009; 38: 775 - 781

338 Muscatiello N, Salcuni A, Macarini L et al. Treatment of a pancreatic endocrine tumor by ethanol injection guided by endoscopic ultrasound. Endoscopy 2008; 40 (Suppl 2): E258 - E259

339 DeWitt J, Mohamadnejad M. EUS-guided alcohol ablation of metastatic pelvic lymph nodes after endoscopic resection of polypoid rectal cancer: the need for long-term surveillance. Gastrointest Endosc 2011; 74: $446-447$

340 DiMaio CJ, Krishnan S, Roayaie S. EUS-guided ethanol ablation for management of metastatic hepatocellular carcinoma. J Interv Gastroenterol 2014; 4: 13-14

341 Gunter E, Lingenfelser T, Eitelbach F et al. EUS-guided ethanol injection for treatment of a GI stromal tumor. Gastrointest Endosc 2003; 57: 113-115

342 Barclay RL, Perez-Miranda M, Giovannini M. EUS-guided treatment of a solid hepatic metastasis. Gastrointest Endosc 2002; 55: 266-270

$343 \mathrm{Hu} \mathrm{YH,} \mathrm{Tuo} \mathrm{XP,} \mathrm{Jin} \mathrm{ZD} \mathrm{et} \mathrm{al.} \mathrm{Endoscopic} \mathrm{ultrasound} \mathrm{(EUS)-guided} \mathrm{etha-}$ nol injection in hepatic metastatic carcinoma: a case report. Endoscopy 2010; 42 (Suppl 2): E256-257

344 Artifon EL, Lucon AM, Sakai P et al. EUS-guided alcohol ablation of left adrenal metastasis from non-small-cell lung carcinoma. Gastrointest Endosc 2007; 66: 1201 - 1205

345 Chang KJ, Nguyen PT, Thompson JA et al. Phase I clinical trial of allogeneic mixed lymphocyte culture (cytoimplant) delivered by endoscopic ultrasound-guided fine-needle injection in patients with advanced pancreatic carcinoma. Cancer 2000; 88: 1325 - 1335

346 Hirooka $Y$, Itoh A, Kawashima $\mathrm{H}$ et al. A combination therapy of gemcitabine with immunotherapy for patients with inoperable locally advanced pancreatic cancer. Pancreas 2009; 38: e69-e74

347 Nonogaki $K$, Hirooka Y, Itoh A et al. Combined treatment with immunotherapy and chemotherapy using endoscopic ultrasonography: A phase 1 trial as first line treatment in patients with locally advanced pancreatic carcinoma (abstract). Gastrointest Endosc 2007; 65: AB207

348 Irisawa A, Takagi T, Kanazawa $M$ et al. Endoscopic ultrasound-guided fine-needle injection of immature dendritic cells into advanced pancreatic cancer refractory to gemcitabine: a pilot study. Pancreas 2007; 35: 189 - 190

349 Chang KJ, Reid T, Senzer N et al. Phase I evaluation of TNFerade biologic plus chemoradiotherapy before esophagectomy for locally advanced resectable esophageal cancer. Gastrointest Endosc 2012; 75: 1139 - 1146 e 1132

350 Hecht JR, Farrell JJ, Senzer $N$ et al. EUS or percutaneously guided intratumoral TNFerade biologic with 5-fluorouracil and radiotherapy for first-line treatment of locally advanced pancreatic cancer: a phase I/II study. Gastrointest Endosc 2012; 75: 332 - 338

351 Herman JM, Wild AT, Wang $H$ et al. Randomized phase III multi-institutional study of TNFerade biologic with fluorouracil and radiotherapy for locally advanced pancreatic cancer: final results. J Clin Oncol 2013; 31: 886-894

352 Hecht JR, Bedford R, Abbruzzese JL et al. A phase I/II trial of intratumoral endoscopic ultrasound injection of ONYX-015 with intravenous gemcitabine in unresectable pancreatic carcinoma. Clin Cancer Res 2003; 9: $555-561$

353 Levy MJ, Alberts SR, Chari ST et al. EUS guided intra-tumoral gemcitabine therapy for locally advanced and metastatic pancreatic cancer (abstract). Gastrointest Endosc 2011; 73: AB144-AB145

354 Buscarini E, Savoia A, Brambilla G et al. Radiofrequency thermal ablation of liver tumors. Eur Radiol 2005; 15: 884-894

355 Fegrachi S, Besselink MG, van Santvoort HC et al. Radiofrequency ablation for unresectable locally advanced pancreatic cancer: a systematic review. HPB (Oxford) 2014; 16: 119-123

356 Rombouts SJ, Vogel JA, van Santvoort HC et al. Systematic review of innovative ablative therapies for the treatment of locally advanced pancreatic cancer. Br J Surg 2015; 102: 182-193

357 Varadarajulu S, Jhala NC, Drelichman ER. EUS-guided radiofrequency ablation with a prototype electrode array system in an animal model (with video). Gastrointest Endosc 2009; 70: 372 - 376 
358 Goldberg SN, Mallery S, Gazelle GS et al. EUS-guided radiofrequency ablation in the pancreas: results in a porcine model. Gastrointest Endosc 1999; 50: $392-401$

359 Sethi A, Ellrichmann M, Dhar S et al. Endoscopic ultrasound-guided lymph node ablation with a novel radiofrequency ablation probe: feasibility study in an acute porcine model. Endoscopy 2014; 46: 411 415

360 Gaidhane M, Smith I, Ellen $K$ et al. Endoscopic Ultrasound-Guided Radiofrequency Ablation (EUS-RFA) of the Pancreas in a Porcine Model. Gastroenterol Res Pract 2012; 2012: 431451

361 Kim HJ, Seo DW, Hassanuddin A et al. EUS-guided radiofrequency ablation of the porcine pancreas. Gastrointest Endosc 2012; 76: 1039 1043

362 Hlavsa J, Prochazka V, Kala Z et al. Radiofrequency ablation of pancreatic neuroendocrine tumor. Klin Onkol 2011; 24: 209-215

363 Arcidiacono PG, Carrara S, Reni $M$ et al. Feasibility and safety of EUSguided cryothermal ablation in patients with locally advanced pancreatic cancer. Gastrointest Endosc 2012; 76: 1142-1151

364 Chan HH, Nishioka NS, Mino $M$ et al. EUS-guided photodynamic therapy of the pancreas: a pilot study. Gastrointest Endosc 2004; 59: 95-99

365 Yusuf TE, Matthes K, Brugge WR. EUS-guided photodynamic therapy with verteporfin for ablation of normal pancreatic tissue: a pilot study in a porcine model (with video). Gastrointest Endosc 2008; 67: $957-961$

366 Di Matteo F, Martino M, Rea R et al. EUS-guided Nd:YAG laser ablation of normal pancreatic tissue: a pilot study in a pig model. Gastrointest Endosc 2010; 72: $358-363$

367 Di Matteo F, Grasso R, Pacella CM et al. EUS-guided Nd:YAG laser ablation of a hepatocellular carcinoma in the caudate lobe. Gastrointest Endosc 2011; 73: $632-636$

368 Sun S, Xu H, Xin J et al. Endoscopic ultrasound-guided interstitial brachytherapy of unresectable pancreatic cancer: results of a pilot trial. Endoscopy 2006; 38: 399-403

369 Sun S, Ge N, Wang S et al. Pilot trial of endoscopic ultrasound-guided interstitial chemoradiation of UICC-T4 pancreatic cancer. Endoscopic Ultrasound 2012:1:41-47

370 Martinez-Monge R, Subtil JC, Lopez-Picazo JM. Transoesophageal endoscopic-ultrasonography-guided 125 I permanent brachytherapy for unresectable mediastinal lymphadenopathy. Lancet Oncol 2006; 7: $781-783$

371 Varadarajulu S, Trevino JM, Shen S et al. The use of endoscopic ultrasound-guided gold markers in image-guided radiation therapy of pancreatic cancers: a case series. Endoscopy 2010; 42: 423 - 425

372 DiMaio CJ, Nagula S, Goodman KA et al. EUS-guided fiducial placement for image-guided radiation therapy in GI malignancies by using a 22-gauge needle (with videos). Gastrointest Endosc 2010; 71: $1204-1210$

373 Fernandez DC, Hoffe SE, Barthel JS et al. Stability of endoscopic ultrasound-guided fiducial marker placement for esophageal cancer target delineation and image-guided radiation therapy. Pract Radiat Oncol 2013; 3: $32-39$

374 Yang J, Abdel-Wahab M, Ribeiro A. EUS-guided fiducial placement before targeted radiation therapy for prostate cancer. Gastrointest Endosc 2009; 70: 579-583

375 Yang J, Abdel-Wahab M, Ribeiro A. EUS-guided fiducial placement after radical prostatectomy before targeted radiation therapy for prostate cancer recurrence. Gastrointest Endosc 2011; 73: 1302 1305

376 Machiels M, van Hooft J, Jin P et al. Endoscopy/EUS-guided fiducial marker placement in patients with esophageal cancer: a comparative analysis of 3 types of markers. Gastrointest Endosc 2015; 82: 641 649

377 Choi JH, Seo DW, Park do $H$ et al. Fiducial placement for stereotactic body radiation therapy under only endoscopic ultrasonography guidance in pancreatic and hepatic malignancy: practical feasibility and safety. Gut Liver 2014; 8: 88-93

378 Park WG, Yan BM, Schellenberg D et al. EUS-guided gold fiducial insertion for image-guided radiation therapy of pancreatic cancer: 50 successful cases without fluoroscopy. Gastrointest Endosc 2010; 71: $513-518$

379 Sanders MK, Moser AJ, Khalid A et al. EUS-guided fiducial placement for stereotactic body radiotherapy in locally advanced and recurrent pancreatic cancer. Gastrointest Endosc 2010; 71: 1178-1184

380 Law JK, Singh VK, Khashab MA et al. Endoscopic ultrasound (EUS)guided fiducial placement allows localization of small neuroendocrine tumors during parenchymal-sparing pancreatic surgery. Surg Endosc 2013; 27: 3921 - 3926

381 Majumder S, Berzin TM, Mahadevan A et al. Endoscopic ultrasoundguided pancreatic fiducial placement: how important is ideal fiducia geometry? Pancreas 2013; 42: 692-695

382 Khashab MA, Kim KJ, Tryggestad EJ et al. Comparative analysis of traditional and coiled fiducials implanted during EUS for pancreatic cancer patients receiving stereotactic body radiation therapy. Gastrointest Endosc 2012; 76: 962 - 971

383 Davila Fajardo R, Lekkerkerker SJ, van der Horst A et al. EUS-guided fiducial markers placement with a 22-gauge needle for image-guided radiation therapy in pancreatic cancer. Gastrointest Endosc 2014; 79 $851-855$

384 Draganov PV, Chavalitdhamrong D, Wagh MS. Evaluation of a new endoscopic ultrasound-guided multi-fiducial delivery system: a prospective non-survival study in a live porcine model. Dig Endosc 2013 25: 615-621 